\title{
WestVirginiaUniversity
}

THE RESEARCH REPOSITORY @ WVU

Graduate Theses, Dissertations, and Problem Reports

2004

\section{Pain-related acceptance and physical impairment in individuals with chronic pain}

Kevin E. Vowles

West Virginia University

Follow this and additional works at: https://researchrepository.wvu.edu/etd

\section{Recommended Citation}

Vowles, Kevin E., "Pain-related acceptance and physical impairment in individuals with chronic pain" (2004). Graduate Theses, Dissertations, and Problem Reports. 2157.

https://researchrepository.wvu.edu/etd/2157

This Dissertation is protected by copyright and/or related rights. It has been brought to you by the The Research Repository @ WVU with permission from the rights-holder(s). You are free to use this Dissertation in any way that is permitted by the copyright and related rights legislation that applies to your use. For other uses you must obtain permission from the rights-holder(s) directly, unless additional rights are indicated by a Creative Commons license in the record and/ or on the work itself. This Dissertation has been accepted for inclusion in WVU Graduate Theses, Dissertations, and Problem Reports collection by an authorized administrator of The Research Repository @ WVU.

For more information, please contact researchrepository@mail.wvu.edu. 
Pain-Related Acceptance and Physical Impairment in Individuals with Chronic Pain

Kevin E. Vowles

\begin{abstract}
Dissertation submitted to the Eberly College of Arts and Sciences at West Virginia University in partial fulfillment of the requirements for the degree of
\end{abstract}
Doctor of Philosophy
in
Clinical Psychology
Daniel W. McNeil, Ph.D., Chair
Amy Combs-Lane, Ph.D.
Richard T. Gross, Ph.D.
Kevin T. Larkin, Ph.D.
B. Kent Parker, Ph.D.
Department of Psychology

\author{
Morgantown, West Virginia \\ 2004
}

Keywords: Clinical Psychology; Chronic Pain; Acceptance; Function Copyright 2004 Kevin E. Vowles 


\author{
ABSTRACT \\ Pain-Related Acceptance and Physical Impairment in Individuals with Chronic Pain
}

Kevin E. Vowles

Treatments using acceptance-based approaches have been utilized for a variety of health care concerns with data regarding their application to a chronic pain population recently emerging. These approaches may be particularly suited to chronic pain as they target potentially harmful avoidance and ineffective pain control strategies. Acceptance of chronic pain is related to psychosocial constructs generally (e.g., depression, pain-related anxiety); however, its relation to the overt behavioral variables associated with such states remains unevaluated. The present investigation assessed the specific effects of an acceptance-based versus control-based instructional set on demonstrated physical impairment in 74 individuals with chronic low back pain. Participants completed a baseline evaluation of physical impairment and then listened to audiotaped instructions detailing one of three approaches (pain acceptance, pain control, and no change). They then repeated the physical impairment assessment and were asked to utilize the approach detailed in the audiotaped instructions to guide behavior during the tasks. Results indicated that, after controlling for baseline levels of physical impairment, individuals receiving the acceptance instructions were less physically impaired at the second assessment compared to the other two groups, which did not differ from one another. Further, individuals in the acceptance group exhibited a $16.3 \%$ improvement in impairment level, while the pain control group worsened by $8.3 \%$ and the no change group worsened by $2.5 \%$; these changes were also statistically different from one another. Group membership was generally unrelated to pain reported during the physical impairment assessment, a finding theoretically consistent with acceptance models. These results lend further support to the value of acceptance in actual patient behavior, as well as the ability of a relatively simple acceptance-based intervention to improve functioning over the short term in a sample of individuals with chronic pain. Additionally, the findings highlight some of the possible risks in focusing solely on pain control and avoidance, as this method was associated with poorer physical performance compared with the acceptance group. Although the present study was analogue in nature, and thus its findings cannot be directly attributable to clinical realms, it does provide some initial support for these types of approaches within chronic pain. 


\section{Table of Contents}

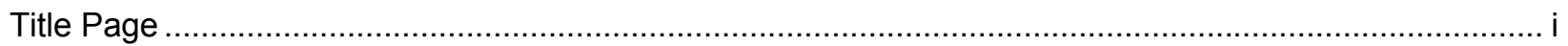

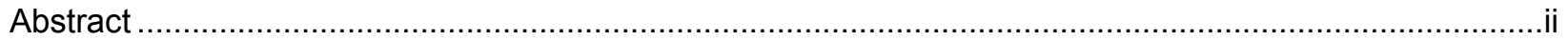

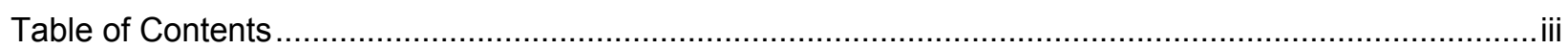

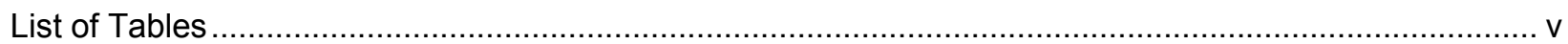

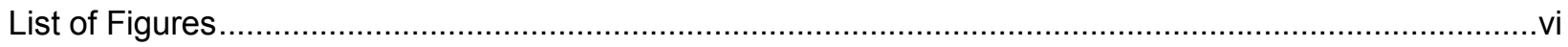

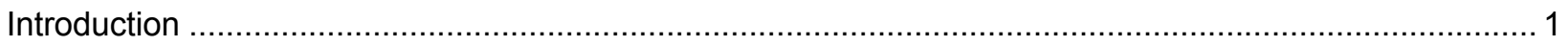

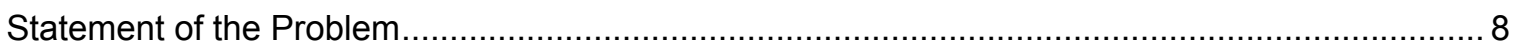

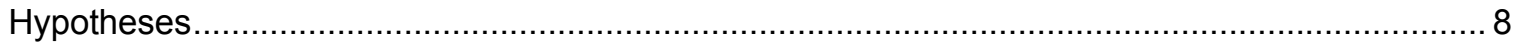

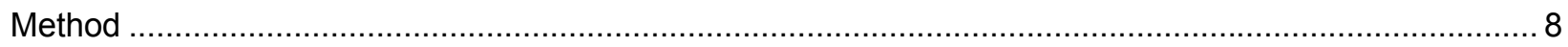

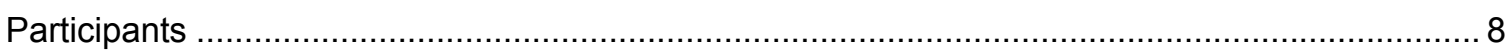

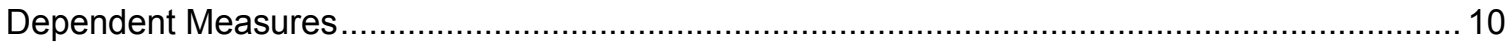

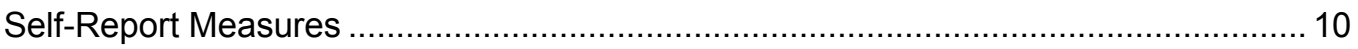

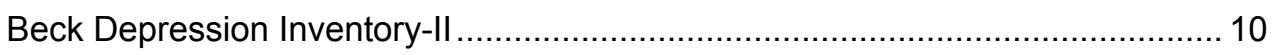

Chronic Pain Acceptance Questionnaire ......................................................... 10

Fear of Pain Questionnaire-Short Form ..................................................... 10

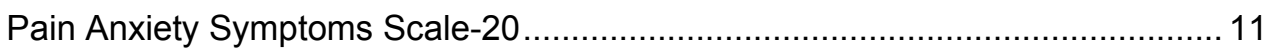

Short Form McGill Pain Questionnaire ........................................................ 11

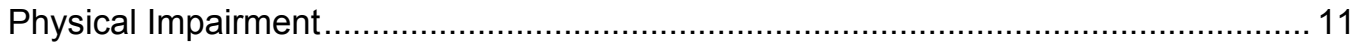

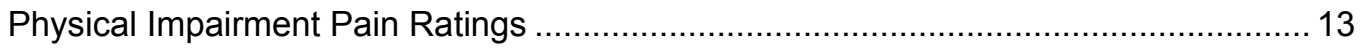

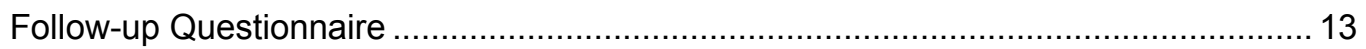

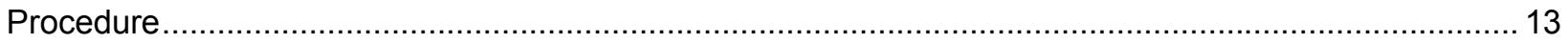

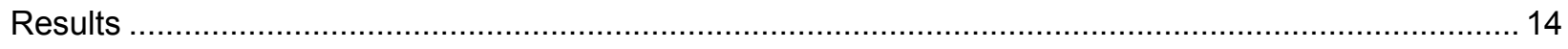

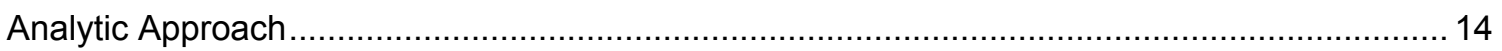

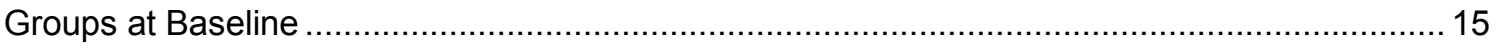

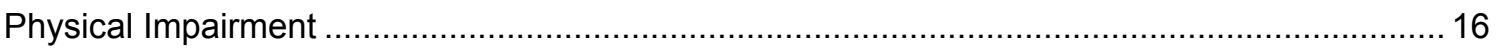

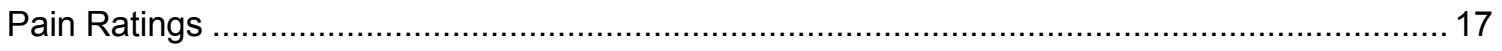

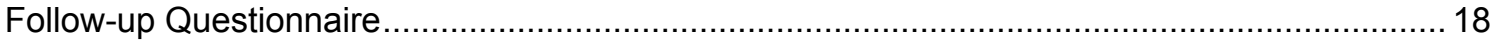




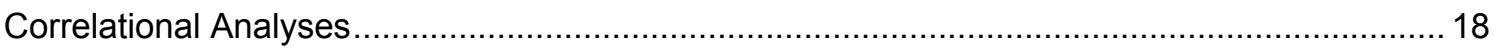

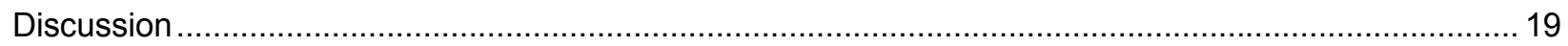

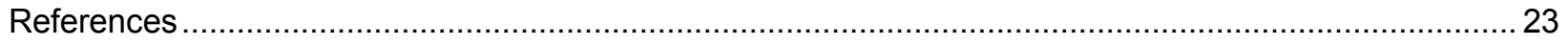

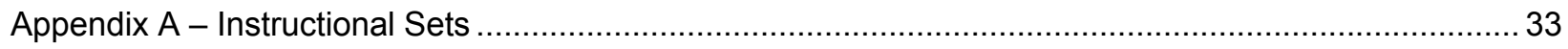

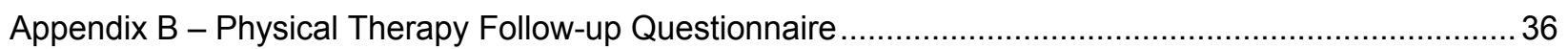

Appendix C - ANOVA Table for Demographic and Self-Report Measures ........................................... 37

Appendix D - ANOVA Table for Baseline Physical Impairment Index Scores ..................................... 38

Appendix E - ANOVA Table for Pain Ratings During Baseline Completion of the Physical

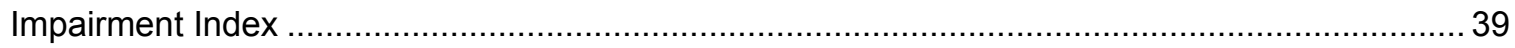

Appendix F - ANCOVA Table for Physical Impairment Index Subscales and Total Score...................... 40

Appendix G - ANOVA Table for Change Scores on Physical Impairment Subscales and Total Score..... 41

Appendix H - ANCOVA Table for Physical Impairment Index Pain Ratings ........................................ 42

Appendix I - ANOVA Table for Change Scores on Physical Impairment Pain Ratings ......................... 43

Appendix J - ANOVA Table for Follow-up Questionnaire Concerning the Instructional Sets .................. 45

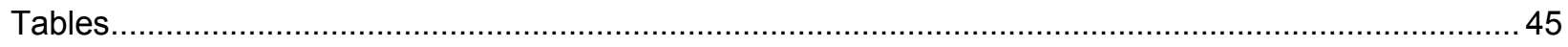

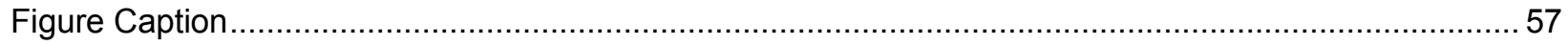

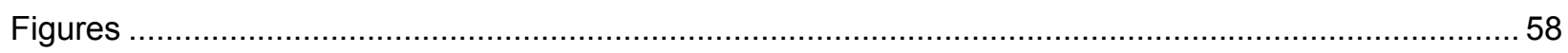




\section{List of Tables}

1. Descriptive Information for Demographic and Self-Report Measures by Instructional Group...............45

2. Mean (Standard Deviation) Values for the Physical Impairment Index ............................................ 47

3. Mean (Standard Deviation) Values for the Physical Impairment Index Pain Ratings.......................... 49

4. Estimated Marginal Means (Standard Deviation) for Post-Instruction Physical Impairment Index

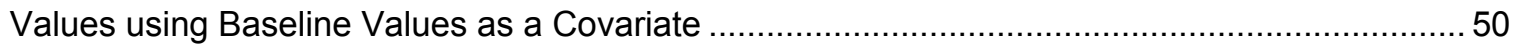

5. Average Raw Change (Standard Deviation) in Physical Impairment Index Values ............................ 51

6. Estimated Marginal Means (Standard Deviation) for Post-Instruction Physical Impairment Index Pain Ratings using Baseline Values as a Covariate .................................................. 52

7. Average Raw Change (Standard Deviation) in Physical Impairment Index Pain Ratings ..................... 53

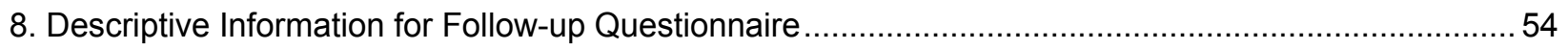

9. Correlations Among Physical Impairment Index Variables and Self-Report Measures .......................55

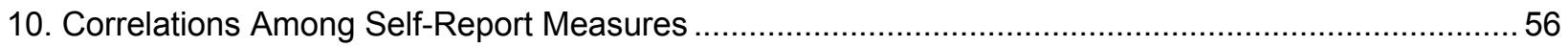




\section{List of Figures}

1. Physical Impairment Index Total Scores at Baseline and Post-Instruction Across Groups 
Pain Related Acceptance and Physical Impairment in Individuals with Chronic Pain The concept of acceptance in chronic pain has recently received increased attention in both research and clinical realms. Reasons for this increased focus likely include two factors, each of which represent shortcomings of the current models of treatment for severe, persistent pain. First, although chronic pain continues to be a widespread problem within societal and health care realms, treatments often are only moderately effective (Deyo, 1983; Gatchel, 1999; Hazard, 1991; Turk, 1990; 1996), and a bonafide "cure" remains elusive. Recently published longitudinal data, collected over a four-year period, regarding the course of chronic pain suggest that pain severity remains relatively stable over time and that average annual recovery rates are only about $5 \%$ (Elliott, Smith, Hannaford, Smith, \& Chambers, 2002). Therefore, there is a need for new, and more effective, treatment modalities within this population. Second, the historical focus of treatment for chronic pain has been on pain reduction with the assumption that as pain is reduced, function will increase (Vlaeyen \& Morley, 2004). This assumption has not proven to be valid, and some available treatment modalities for chronic pain can have unexpected negative effects on function and rehabilitation (Arnoff, 1991; Harden, 2002; Deyo, Nachemson, \& Mirza, 2004; Jamison, Anderson, Peeters-Asdourian, \& Ferrante, 1994; Waddell, 1987) or only decrease pain with no subsequent improvement in function (i.e., spinal cord stimulator implantation; Kemler et al., 2000).

Given these shortcomings, an increased evaluation of function, and the role that it serves in chronic pain distress and disability, has been undertaken with the results often supporting the efficacy of functional-based approaches that improve activity level in some patient populations (Bendix, Bendix, Labriola, Haestrup, \& Ebbehoj, 2000; Haldorsen et al., 2002; Waddell, Feder, \& Lewis, 1997). Further, data are amassing to support the importance of changes in psychosocial variables and functional level over changes in pain severity in the prediction of treatment-mediated improvement in symptoms (McCracken, Gross, \& Eccleston, 2002; Penny, Purves, Smith, Chambers, \& Smith, 1999; Summers, Rapoff, Varghese, Porter, \& Palmer, 1991). In addition, a series of recent studies have supported the role of these psychosocial variables in actual patient behavior, including increasing the probability of successful return to work (Vowles \& Gross, 2003; Vowles, Gross, \& Sorrell, 2004; Watson, Booker, Moores, \& Main, 2004). Thus, a shift is occurring within the treatment of chronic pain, one that does not 
focus on pain reduction as the primary method of increasing function, but instead focuses on functional improvements, in and of themselves, as targets of treatment.

Acceptance and Commitment Therapy (ACT; Hayes, Strosahl, \& Wilson, 1999) represents a promising approach to the treatment of chronic pain because, like other recently developed clinical strategies (e.g., Integrative Couples Therapy: Jacobson, Christensen, Prince, Cordova, \& Eldridge, 2000; Dialectical Behavior Therapy: Linehan, 1993; Linehan et al., 1999; Mindfulness-Based Cognitive Therapy: Teasdale et al., 2000), the focus of ACT is on changing overt behavior and functioning, rather than internal sensations or thoughts. The underpinnings of ACT and acceptance-based interventions are consistent with behavior analytic theories and views of behavior. As such, behavior is assumed to occur as a result of both historical and situational variables and every action, including private ones (e.g., thinking \& feeling; Baum, 1994; Linscott \& DiGiuseppe, 1998), of an organism is defined as behavior. These interventions also make use of many well-established behavioral principles and techniques such as reinforcement, extinction, exposure, and generalization/discrimination (Anderson, Hawkins, \& Scotti, 1997), which also have proven relevance within chronic pain (Flor, Knost, \& Birbaumer, 2002; Jolliffe \& Nicholas, 2004). . In addition to these behavioral foundations, acceptance-based theories also draw from literature concerned with mindfulness (defined as an awareness of current contextual variables; Baer, 2003; Walsh, 1980), as well as primarily Eastern religions (e.g., Buddhism; Kabat-Zinn, 2003; Rahula, 1974, pp. 16-28) and existentialist therapies that discuss the universality (and unavoidability) of human suffering. From these foundations, the prevailing concepts in acceptance-based theories are: (a) suffering and experiencing negative thoughts, feelings, and sensations are a normal part of the human experience, (b) unsuccessful attempts to control or avoid this suffering contribute to the increased experience of it, and (c) commitment to behavior change and the pursuit of personally-relevant values and goals are the most efficient means of achieving positive outcomes (Hayes, Strosahl, et al.; Kohlenberg, Hayes, \& Tsai, 1993).

Within chronic pain, the concept that individuals might best "accept" and "learn to live with" chronic pain in order to effectively cope with it is not new (e.g., Fordyce, 1976). Exactly how patients may accomplish this feat, however, has heretofore remained obscured. In part, this problematic issue is due to differing definitions of acceptance among individuals (Risdon, Eccleston, Crombez, \& McCracken, 2003) 
and the fact that acceptance and "giving up hope" often are thought to be the same by clinical chronic pain populations (McCracken, Eccleston, \& Bell, in press; Viane et al., 2003). Therefore, a comprehensive definition of acceptance is necessary in order to be operationalized in a clinical setting. Within a treatment context, acceptance can be defined as experiencing and living life in a satisfying and rewarding manner in spite of aversive thoughts, sensations, or experiences (Hayes, 1994; Hayes, Strosahl, et al., 1999; McCracken, 1998). Therefore, the focus of treatment is on changing overt (i.e., observable) behaviors, although it is recognized that private events can be distressing. The assumption then, is that once individuals come into contact with natural and reinforcing environmental contingencies, the impact of the distressing sensations will be minimized, even while they continue to occur. With regard to chronic pain, an individual may not be able to change the fact that pain is frequently experienced and is unpleasant; however, he or she may be able to alter the impact that this pain has on day-to-day functioning (e.g., recreational, social, occupational activities), which is the goal of these treatments. Although there is a lack of controlled, large sample, experimental studies, a number of small $N$ designs and case studies that support the efficacy of acceptance-based treatments have been reported in the literature. Specifically, treatments using acceptance-based approaches have been used across a wide variety of behavioral disorders, including post-traumatic stress disorder, depression, anxiety, substance abuse, anorexia nervosa, and borderline personality disorder (Batten \& Hayes, in press; Dougher, 2002; Dougher \& Hackbert, 1994; Hayes, Jacobson, Follette, \& Dougher, 1994; Heffner, Sperry, Eifert, \& Detweiler, 2002; McMain, Korman, \& Dimeff, 2001, respectively). In addition, a recently published randomized controlled study performed by Bach and Hayes (2002) indicated that a brief ACT intervention was effective at decreasing inpatient rehospitalization rates among individuals experiencing the positive symptoms of schizophrenia (i.e., delusions, hallucinations).

There appear to be two important contributions of acceptance-based treatments that target problems specifically involved in chronic pain. The first, as discussed by Hayes, Strosahl et al. (1999), is that acceptance-based treatments view private events (e.g., thoughts, emotions) as difficult, if not impossible, to control. This assertion has received empirical support with regard to thought suppression generally (Rassin, Merckelback, \& Muris, 2000; Wegner, 1994; Wegner, Schneider, Carter, \& White, 1987), as well as the suppression of anxious thoughts (Eifert \& Heffner, 2003; Koster, Rassin, Crombez, 
\& Naring, 2003) and acute painful sensations (Cioffi \& Holloway, 1993; Sullivan, Rouse, Bishop, \& Johnston, 1997). Not only is it difficult to control some private events, but across these studies, attempts to suppress private events contributed to an increase in the occurrence of the event. For example, Sullivan et al. found that individuals instructed to suppress thoughts of pain during cold pressor tasks reported more severe pain, as well as a higher incidence of fearful thoughts, compared to nonsuppressors. Relatedly, in an investigation examining two "naturally-occurring" thought management strategies, suppression and acceptance, Marcks and Woods (in press) reported that thought suppressors report more frequent intrusive thoughts, greater distress from these thoughts, and a greater urge to "do something" to counteract or manage these thoughts compared with those who reported accepting these intrusive thoughts. Finally, an attentional distraction task had no reducing effect on pain ratings during the performance of a pain-inducing lifting task and was associated with increased pain reports immediately following the task, relative to performing the task with no distraction in a sample of chronic pain patients (Goubert, Crombez, Eccleston \& Devulder, 2004). The observed effects of this distraction task parallel findings in the thought suppression literature generally, although there has yet to be an in-depth analysis of distraction as a helpful or harmful method of coping with chronic pain. This finding reflects problems with the coping literature in general, where there is not yet a consensus regarding which coping methods in chronic pain are most helpful (Jensen, Turner, \& Romano, 1991; McCracken \& Eccleston, 2003). Thus, it appears that the management of uncomfortable thoughts or sensations (i.e., pain) by attempts to suppress their occurrence is largely ineffective and can contribute to paradoxical increases in their frequency, as well as subjective levels of distress.

With regard to chronic pain, a similar concept appears to hold true; pain not only is difficult to control, but that struggling, and failing, to control pain is an ineffective treatment strategy. Further, this unsuccessful struggle actually can contribute to increased distress and disability (Gatchel, 1996) and repeated failures to control pain have been associated with increased emotional and physiological responding, but not with increased pain reports (Janssen, Spinhoven, \& Arntz, 2004). Others have hypothesized that continued failures to control pain over the long-term can, indeed, increase pain reports (McCracken, Faber, \& Janek, 1998; Robinson \& Riley, 1999; Turk, Okifuji, \& Scharff, 1995) although data are not available with regard to chronic pain. Given that unsuccessfully struggling to control chronic pain 
intensity, which perhaps is uncontrollable, is ineffective and can have adverse effects, the acceptancebased treatments attempt to mobilize individuals to focus less on pain control and increasingly on other, more controllable, facets of life.

The second component of the acceptance-based treatments that is particularly applicable to chronic pain involves the problems that are caused by avoidance of aversive thoughts and sensations. Given that avoidance can be conceptualized as any behavior intended to decrease the probability of the occurrence of an aversive event (private or public), it is a natural response to any unpleasant situation. Furthermore, it is generally effective in the short-term (but, as in the case of phobia, not in the long-term) when the event can be successfully avoided. When the event cannot be avoided (e.g., certain feelings of pain), however, it can lose its adaptive value and continued unsuccessful attempts at avoidance can contribute to decreased function and quality of life (Hayes, Wilson, Gifford, Follette, \& Strosahl, 1996). Further, continued avoidance behavior can have significant detrimental effects in areas as diverse as posttraumatic stress disorder (Boeschen, Koss, Figueredo, \& Coan, 2001), depression (DeGenova, Patton, Jurich, \& MacDermid, 1994), substance abuse (Cooper, Russel, Skinner, Frone, \& Mudar, 1992), and anxiety (Feldner, Zvolensky, Eifert, \& Spira, 2003). As a whole, the available literature indicates that excessive avoidance contributes to significant distress, and more importantly, that confrontation of the unpleasant situations is much more adaptive and beneficial (Griest, Marks, Berlin, Gournay, \& Noshirvani, 1980; Robinson \& Hayes, 1999).

Avoidance behavior within the context of chronic pain is not an effective coping strategy (see Roth \& Cohen, 1986 and Williams, 1996 for reviews), although it unfortunately appears to be the normative coping style in individuals with chronic pain presenting to treatment clinics (Crombez, Vervaet, Lysens, Baeyens, \& Eelen, 1998). In particular, the avoidance of potentially painful or harmful situations is acknowledged to be one of the key characteristics and contributors to pain-related disability (Arnoff \& McAlary, 1992; Crombez et al.; Fordyce, 1976; Kori, Miller, \& Todd, 1999; Phillips, 1987); individuals who utilize primarily avoidant coping strategies (e.g., praying/hoping, catastrophizing) are more dysfunctional in coping with chronic pain (Geisser, Robinson, \& Henson, 1994; Keefe, Lumley, Anderson, Lynch, \& Carson, 2001). Finally, a recently published study by Vowles, Zvolensky, Gross, and Sperry (2004) indicated that self-reported avoidance behaviors in response to chronic pain were positively predictive of 
interference in daily activities over and above levels of affective distress and pain-related cognitions. The acceptance-based treatments are particularly applicable to decreasing avoidance behaviors in chronic pain, because acceptance, by definition, incorporates a willingness to confront aversive experiences, such as pain.

Studies specifically evaluating the relation between acceptance and pain generally have indicated that lower acceptance is associated with greater distress and disability. Acceptance of the disability associated with pain, as assessed by the Acceptance of Disability Scale (Linkowski, 1971), was inversely related to pain severity in 42 individuals with both spinal cord injuries (i.e., fractures leading to quadriplegia or paraplegia) and ongoing pain complaints (Summers et al., 1991). Furthermore, the presence of chronic pain appears to be a risk factor for decreased levels of disability acceptance and adaptation, as reported by Li and Moore (1998) in their analyses of 1,266 individuals diagnosed with a "disabling condition" (e.g., mental retardation, deafness/blindness, chemical dependency, learning disability).

McCracken and colleagues have published a series of studies investigating the role of acceptance specifically in chronic pain. The first published study evaluating pain-related acceptance included 160 patients seeking treatment for chronic pain and indicated that lower acceptance was associated with higher reports of pain intensity, more pain-related affective distress (e.g., pain-related anxiety, depression), higher levels of physical and psychosocial disability, lower activity levels, and poorer work status (McCracken, 1998; 1999). A subsequent evaluation also indicated that individuals with higher levels of acceptance tended to cope with pain in a much more adaptive manner compared to individuals more dysfunctional in their coping style (McCracken, Spertus, Janeck, Sinclair, \& Wetzel, 1999). Further, the significance of acceptance remained even after controlling for pain intensity, depression, and fear of pain. When compared with a traditional measure of pain-related coping (i.e., the Coping Strategies Questionnaire; CSQ; Rosenstiel \& Keefe, 1983), acceptance of pain was a more valuable predictor of adjustment across measures of pain intensity, depression/anxiety, disability levels, and work status than CSQ subscales in a sample of 230 chronic pain patients (McCracken \& Eccleston, 2003). These studies serve to provide a basis for further research by supporting the role of acceptance in accounting for established measures of distress and disability in chronic pain. However, they are somewhat limited in 
that they all emerged from a single laboratory, share some overlap in sample, and use cross-sectional self-report measurements. Nonetheless, these initial forays into the area have answered many of the preliminary questions in the field regarding the importance of acceptance and its distinctness from traditional measures of pain, emotion, anxiety, or coping.

To date, the only published report attempting to determine the effects of changing levels of acceptance involved laboratory-induced pain in a non-clinical sample of undergraduate students. Hayes, Bissett et al. (1999) manipulated pain coping style in a group of 30 undergraduates exposed to a laboratory pain induction challenge (i.e., cold pressor). Participants assigned to the acceptance group were given a rationale for acceptance of painful sensations, which encouraged them to take note of the aversive feelings, and their associated thoughts, but not to allow these sensations to control behavior. The study's results indicated that individuals in the acceptance condition had greater pain tolerance times than individuals in either of the other two conditions, which were control-based (i.e., rationale provided techniques to control pain) and education "placebo" (i.e., rationale provided pain education). Interestingly, no differences were observed in self-report ratings of an aggregate aversiveness variable composed of ratings of pain, unpleasantness, and amount of sensation. Thus, by taking a perspective that pain (and other aversive private events) was not necessarily linked with behavioral actions (e.g., escape, avoidance), pain tolerance was increased.

\section{Statement of the Problem}

Although the available research strongly supports the relevance of acceptance within chronic pain, it is limited in a number of ways. First, all available data are correlational in nature, which obscures the causal relations between acceptance and pain-related disability. Thus, there is a need for studies investigating differences between groups that are "accepting" or "unaccepting" (e.g., high levels of desire for or pursuit of pain control) of chronic pain. A second limitation is that most of the data were collected at a single point in time. Such cross-sectional data limits causal relations, and may be influenced by situational variables at the time of assessment (e.g., clinical setting vs. laboratory setting). Published longitudinal data investigating experimental manipulations or whether the construct of acceptance is sensitive to treatment are needed, as is information regarding changes in acceptance that occur over time. The available data regarding acceptance and chronic pain also are limited in that all published 
studies rely solely on self-report measures, with the exception of the 1999 Hayes, Bissett et al. study of acute pain responding in a nonclinical sample. Therefore, shared method variance may have inflated correlations between variables in these studies. The use of measures of physical or vocational ability would allow one to evaluate how acceptance of chronic pain is related to measures of overt behavior. Based on these limitations, the present study sought to investigate pain-related acceptance by using an experimental paradigm in an applied clinical setting. Furthermore, the effects of changing the context (i.e., acceptance vs. control vs. no change) within which participants approached standardized physical tasks on task performance were assessed in a mixed factorial design. The relation between baseline levels of acceptance and initial physical impairment also was assessed.

\section{Hypotheses}

The acceptance group was expected to exhibit improvements in physical impairment after receiving instructions to a greater extent than those receiving instructions to either control pain or not to change behavior. Further, individuals who received instructions to focus on controlling pain were expected to exhibit higher levels of physical impairment relative to those who received acceptance-related instructions. Finally, baseline measures of pain-related acceptance were anticipated to be positively related to ability to perform physical tasks and negatively related to level of physical impairment generally. Consistent with the model of acceptance (Hayes, Strosahl, et al., 1999), as well as other pain-related published studies (e.g., Fishbain et al., 1993; Hildebrandt, Pfingsten, Saur, \& Jansen, 1997; Vowles \& Gross, 2003; Vowles et al., 2004), pain ratings made over the course of physical impairment assessments were expected to have little relation to group membership. Finally, it was hypothesized that self-reported baseline levels of acceptance of chronic pain would account for significant variance in observed physical impairment such that greater acceptance would be associated with less physical impairment.

\section{Method}

\section{Participants}

There were ninety-one individuals with persistent low back pain of greater than three months duration who consented to participate. Each of these individuals was recruited during treatment evaluation appointments from a multidisciplinary functional restoration treatment center. Participation was 
voluntary and predicated on the ability to read and ambulate independently. In addition, the clinic protocol dictated that individuals exhibiting excessively high blood pressure at baseline (greater than 180 systolic or 100 diastolic blood pressure) were not to participate in any assessment involving physical activity. In sum, seventeen (18.7\%) individuals did not complete the experimental protocol: six exhibited BP in excess of stated cut-offs, eight voluntarily discontinued following initial measurement of physical impairment, two had data lost due to an equipment malfunction, and one person was not appropriate given that no low back pain was present.

Demographic and pain-related information was gathered from psychosocial evaluations performed by licensed clinical staff. With regard to the 74 individuals who completed the procedure, the majority were male (70.3\%), married (67.6\%; divorced, 18.9\%; single, 10.8\%; widowed, $2.7 \%$ ), and reported an average of 2.1 children $(S D=0.9)$. Mean age and education were 38.5 years $(S D=8.5$ years; range: $24-52$ years) and 11.4 years $(S D=2.3$ years; range $3-16$ years), respectively. Pain was assessed via 0 (no pain) to 10 (worst possible pain) subjective units of distress scales. Pain at time of assessment was rated $6.4(S D=1.6)$, with average pain, least pain, and worst pain rated as $5.9(S D=$ 1.9), $3.9(S D=1.7)$, and $9.5(S D=0.8)$, respectively. All participants were Caucasian, unemployed, and receiving Worker's Compensation benefits for an occupational injury. The majority of individuals were not receiving or seeking disability (47.3\%), although a substantial proportion of participants were in the midst of applying for it (40.5\%). Additionally, $8.1 \%$ of people were receiving permanent partial disability payments, $1.4 \%$ were receiving temporary total disability payments, and $2.7 \%$ were on United States Social Security Disability. Average duration of pain (20.9 months; $S D=13.3$ months) and unemployment (20.5 months; $S D=12.7$ months) were virtually identical. Primary site of pain for all participants was low back; $43.2 \%$ reported one additional site and $13.5 \%$ reported two additional sites. Of those participants indicating additional pain sites, 50.1\% reported lower extremity pain, $26.9 \%$ upper back/neck pain, $15.4 \%$ upper extremity pain, and $7.6 \%$ other pain locations (e.g., head, pelvis). The majority reported no history of pain-related surgeries (63.5\%; one surgery, $16.2 \%$; two surgeries, $2.7 \%$ ). Finally, $90.5 \%$ of all participants were prescribed one or more medications for pain with $63.5 \%$ prescribed a narcotic, $48.6 \%$ a non-steroidal anti-inflammatory/cox-2 inhibitor, and $29.7 \%$ a benzodiazipine. Sixty-one percent of individuals reported pain relief from prescribed medications. 


\section{Dependent Measures}

\section{Self-Report Measures}

Beck Depression Inventory-II (BDI-II). Associations between pain and depression have been found consistently in both acute (Bengtson, Herlitz, Karlsson, \& Hjalmarson, 1996; Carter et al., 2002) and chronic pain populations (Fishbain, Cutler, Rosomoff, \& Rosomoff, 1997; Krause, Weiner, \& Tait, 1994; Rethelyi, Berghammer, \& Kopp, 2001). Because of its demonstrated utility and association with pain responding within these populations, the BDI-II (Beck, Steer, \& Brown, 1996), a 21-item self-report assessment designed to measure clinically relevant cognitive, affective, and vegetative symptoms of depression, was included. The measure, in either the original or revised version, has been in widespread use for over two decades and its psychometric properties are well supported. A meta-analysis by Beck, Steer, and Garbin (1988) indicated that Cronbach's a values were 0.81 and 0.86 for nonclinical and clinical populations, respectively. Similarly, the test-retest reliability is relatively stable $(r$ range $=.60-.83)$, even across longer durations of time (i.e., one month).

Chronic Pain Acceptance Questionnaire (CPAQ). As a means of measuring acceptance of chronic pain, the revised version of the CPAQ was administered (McCracken, Vowles, \& Eccleston, 2004). This revised measure is based on a questionnaire developed by Geiser (1992) in an unpublished doctoral dissertation and it excludes items with skewed frequency distributions, inappropriate item-total correlations, weak relations with other indices of chronic pain, or those that emerged as consistent singleitem factors. The revised measure has 20 items and two subscales: (a) Activity Engagement (11 items) and (b) Pain Willingness (9 items). Initial evaluations of the measure have supported its psychometric properties (Cronbach's $\alpha=.78-.82$ ) and relation to other medical, physical/functional, and psychosocial variables (e.g., pain intensity, utilization of pain medicines, pain-related healthcare visits, daily rest, physical disability, work status, depression, pain-related anxiety; McCracken et al.).

Fear of Pain Questionnaire - Short Form (FPQ-SF). In order to assess fear of pain, which appears to be one of the key contributors to both pain responding and pain-related disability (McCracken et al., 2002; Lethem, Slade, Troupe, \& Bentley, 1982; Sperry-Clark, McNeil, \& Ciano-Federoff, 1999; Vlaeyen \& Linton, 2000), the FPQ-SF (Kennedy et al., 2001) was administered. Using five-point Likerttype scales, individuals rate their fear of experiencing the pain associated with pain-related events on 
nine items and along three dimensions: severe pain, minor pain, and medical pain. Although the FPQ-SF was recently developed, Kennedy et al.'s findings indicated a high correlation between the short form and the original Fear of Pain Questionnaire-III (McNeil \& Rainwater, 1998), both in terms of correlations between total and subscale scores $\left(r^{\prime} s=.57-.77\right)$ and factor structure (i.e., three-factor solution). Further, measures of internal consistency for the FPQ-SF scales were high (i.e., Cronbach's $\alpha=.74$ to .86 ) and the measure has been shown to correlate well with other measures of pain-related anxiety and fear.

Pain Anxiety Symptoms Scale-20 (PASS-20). Because fear of pain has been shown to be a multidimensional construct (McNeil \& Vowles, 2004; Vlaeyen \& Linton, 2000), an additional measure in this area also was administered. The PASS-20 (McCracken \& Dhingra, 2002) has recently been developed and appears to retain much of the psychometric properties of the longer version of the scale, developed by McCracken, Zayfert, and Gross (1992). As is the case with the longer version of the measure, the PASS-20 allows the calculation of a total score, as well as four subscale scores: cognitive anxiety, escape/avoidance behaviors, feelings of fear, and physiological anxiety. Psychometric data presented by McCracken and Dhingra indicated that the scales of the PASS-20 showed adequate internal consistency (Cronbach's $\alpha=.81)$ and were highly correlated with the original version of the measure $(r$ 's $=.68-.97)$.

Short Form McGill Pain Questionnaire (MPQ-SF). The MPQ-SF (Melzack, 1987) was used as an index of pain severity. The measure allows the assessment of both sensory and affective qualities of pain intensity and has been used extensively in both clinic and research settings. The measure's test-retest reliability has been well established $(r=.67-.85$; Melzack \& Katz, 1992) and internal consistency is reliably above .70 (Melzack \& Katz, 2001).

Physical Impairment

The Physical Impairment Index (PII; Waddell, Somerville, Henderson, \& Newton, 1992) is a standardized measure of functioning for individuals reporting low back pain. The measure utilizes empirically-derived cut-off scores for specific physical tasks and allows the calculation of a total score representing global level of physical impairment. It involves seven separate measures of impairment: four involving flexibility (measured in degrees of movement): total flexion (i.e., bending forward), total extension (i.e., bending backwards), average lateral flexion (i.e., bending to the side), and average 
straight leg raise (i.e., while supine having each leg lifted by a physical therapist until tolerance); two involving strength (measured in endurance time), which were measured while participants were supine on an exam table: active straight leg raise (i.e., lifting both legs 6 inches from the tabletop for $10 \mathrm{~s}$ ) and active sit-up (i.e., lifting both shoulders 6 inches from the tabletop for $10 \mathrm{~s}$ ); and one assessing the presence or absence of spinal tenderness over the spinous processes and inter-spinous ligaments from the T12 to S2 level of the spinal cord. In order to achieve a larger range of responding, participants were timed for responses on the active leg raise and active sit-up for $10 \mathrm{~s}$, rather than the $5 \mathrm{~s}$ that is used to determine presence or absence of impairment by Waddell et al. The $5 \mathrm{~s}$ cut-off was still utilized for calculating the total score. For the flexibility and strength measures, individuals performed each activity until self-defined tolerance was reached.

Based on standardized cut-offs, each of the seven measures can be scored as "impaired" or "not impaired." These values can then be summed to obtain an overall measure of physical impairment which ranges from 0-7 with higher scores indicating increasing impairment. Waddell et al.'s (1992) initial analyses indicated that when administered by physical therapists utilizing the standardized instructions, the demonstrated inter-rater reliability of each of the measures ranged from 0.86 to 0.94 . Additionally, the scale has proven utility in discriminating individuals with and without chronic low back pain (sensitivity: 76\%; specificity: 86\%) and explained significant variance in self-reported disability levels (Waddell et al.). Fritz and Piva (2003) subsequently examined the measure and reported it to have excellent interrater reliability (approximately 24 hours between assessments) for the total score (intraclass coefficient: ICC = .89 ) and the continuous variable individual items (ICC range .87-.91). The categorical variable of spinal tenderness was relatively unreliable, with a Kappa $=.35$. Finally, the measure has been shown to be responsive to interventions (Friedrich, Gittler, Halberstadt, Cermak, \& Heiller, 1998; Fritz \& Piva).

Two physical therapists were trained to administer the PII. Each was trained until able to perform the PII examination technique in accord with instructions provided by Waddell et al. (1992; pp. 626). In total there were six pilot participants; three for each physical therapist. The first participant for both was the author. One pilot participant was videotaped to be scored independently for adherence to standardized instructions. Both of the physical therapists were able to quickly demonstrate mastery of the 
PII, likely because of their graduate level training in the measurement of flexibility, strength, and anatomy/anatomic landmarks, as well as the standardization in instructions provided by Waddell et al. Physical Impairment Pain Ratings.

Participants were asked to verbally rate pain level after completing each of the PII tasks on a scale ranging from zero (no pain) to ten (worst pain imaginable). Pain ratings for each of the tasks were also averaged to compute a composite measure of pain for the entire PII assessment. Similar subjective scales of distress are widely used to assess both psychosocial distress and pain severity (Jensen \& Karoly, 2001; Wolpe, 1958).

Follow-up Questionnaire

The final questionnaire completed by participants served as measure of comprehension of the instructions, as well as a manipulation check. Two of the questions were forced choice (i.e., yes or no). The first asked whether the instructions had been understood and the second if the participant felt that instructions had changed thinking about the seven PII tasks. The final three questions concerned the instructional set's perceived effects on thinking and task performance, as well as usefulness. These questions were answered using 0-10 Likert-type scales with higher ratings indicating greater endorsement of effects. Appendix B displays the questionnaire.

\section{Procedure}

All data were collected as part of a treatment evaluation for an outpatient functional restoration treatment program. Self-report questionnaires were sent to participants one to two weeks before their scheduled appointment and were completed as part of the standard clinical intake that was in place prior to the data collection phase of the present investigation. Upon presenting to the clinic, possible participants were informed about the study and asked to participate; informed consent was then completed where appropriate by a licensed clinical staff member. A total of 124 individuals were asked to participate; $73.4 \%(N=91)$ agreed and were consented. The protocol involved listening to an audiotape through headphones that detailed the physical impairment assessment, completing an assessment of physical impairment administered by a clinic physical therapist, listening to a second set of audiotaped instructions, and completing the physical impairment assessment again. The first instructions were identical for all participants. The second instructions consisted of three sets; each specific set was 
associated with one of the groups. These audiotapes instructed the participants to: (a) concentrate on performance regardless of pain level (acceptance), (b) keep pain at a minimum (pain control), or (c) continue to perform as they had during the initial assessment of bending and stretching (no change). Participants were asked to utilize these instructional sets to guide behavior during the second assessment of physical impairment. The experimental instructional sets were designed to allow participants to adopt one of two approaches to behavioral tasks: Attempting to control pain exacerbation or attempting to control behavior, regardless of pain level. See Appendix A for transcripts of each of these instructional sets. Instructional sets were composed using Hayes, Strosahl, et al.'s (1999) book on theoretical and practical approaches to acceptance. In addition, some of the language used in prior investigations of acceptance (i.e., Bach \& Hayes, 2002; Eifert \& Heffner, 2003; Geiser, 1992; Hayes, Bissett et al., 1999; McCracken et al., in press; McCracken et al., 2004) was used to guide instructional set construction and remain consistent with previously published studies. After participants had finished the physical impairment assessment for the second time, the questionnaire assessing the clarity and effects of the instructional sets was completed.

Assignment to condition was determined by a randomized procedure whereby participant numbers were matched to instructional sets on a case-by-case basis (i.e., 33.3\% chance of each instructional set being assigned to each participant number). The only modification to this assignment formula occurred if a single instructional set was selected for two consecutive cases; when this occurred, that instructional set was excluded from the possible selections for the next case (i.e., $50.0 \%$ chance that either of the two additional instructional sets were assigned). The cassette tapes containing instructional sets displayed a code number that signified which set the tape contained and were stored in sealed folders. Code number and instructional set matching information was kept with the primary author (KV). Clinical staff involved in data collection were kept blind to instructional set assignment and the meaning of code numbers.

Results

\section{Analytic Approach}

In total, 26 individuals (35.1\%) were assigned to the acceptance group, $23(31.1 \%)$ to the pain control group, and $25(33.8 \%)$ to the no change group. There were four steps to the data analytic 
procedure. First, differences among the groups at baseline were assessed via a series of multivariate and univariate analyses of variance (MANOVAs and ANOVAs, respectively) for continuous variables and chisquare analyses for categorical variables. Second, differences among the patient groups with regard to physical impairment levels were assessed in two ways: one analyzing differences in demonstrated PII values and the other analyzing raw change scores (i.e., post-instruction performance - baseline performance) to analyze magnitude of change within groups. Follow-up tests, where appropriate, included one-way ANOVAs using the Tukey-Kramer test for unequal sample sizes. Third, analyses assessing differences in ratings of pain associated with the physical tasks then were performed and were consistent with those utilized for physical impairment. Fourth and finally, relations among acceptance, physical impairment, and other included self-report measures were investigated.

\section{Groups at Baseline}

Mean age, years of education, pain ratings, and number of prescribed medication classes were not statistically different among the groups. Similarly, no differences in pain duration, number of painrelated surgeries, or total number of pain complaints were observed. Responses on the self-report measures were statistically equivalent among the groups. Significant, but statistically equivalent, levels of depressive symptomology were indicated for all groups. Table 1 contains means and SDs and Appendix C displays ANOVA information. Finally, statistically equivalent distributions of gender, $\chi 2(2, N=74)=$ $2.41, p \geq .30$, and marital status, $\chi 2(2, N=74)=10.34, p \geq .11$, were indicated.

An analysis of baseline PII levels indicated a significant effect of group membership for total level of physical impairment, $F(2,73)=3.52, p \leq .05, \eta^{2}=.09$. As illustrated in Figure 1, the acceptance group initially had higher levels of overall physical impairment $(M=4.9, S D=1.4)$ compared with the no change group $(M=4.0, S D=1.3)$. Neither group differed from the pain control group $(M=4.8, S D=1.5)$. There also was a multivariate effect on the individual physical tasks, Wilks' $\lambda=.67, F(12,132)=2.44, p \leq .01$, $\eta^{2}=.18$, indicating a potential failure of random assignment. Descriptive information is located in Table 2. Follow-up one-way ANOVAs, which are detailed in Appendix D, revealed significant group differences for three PII tasks: Straight leg raise, active straight leg raise, and active sit-up. In general, the no change group was less physically impaired at baseline compared to the other groups on these three tasks. Specifically, the pain control group demonstrated significantly lower straight leg raise performance $(M=$ 
26.2 degrees, $S D=14.7$ degrees $)$ than either the acceptance $(M=39.3$ degrees, $S D=18.6$ degrees $)$ or no change group ( $M=41.4$ degrees, $S D=17.8$ degrees). Regarding active straight leg raise, the no change group demonstrated longer endurance times $(M=8.4 \mathrm{~s}, S D=3.1 \mathrm{~s})$ than the acceptance $(M=$ $3.8 \mathrm{~s}, S D=3.4 \mathrm{~s})$ or control group $(M=4.0 \mathrm{~s}, S D=4.2 \mathrm{~s})$. Similarly, the no change group had higher endurance times on the active sit-up $(M=8.4 \mathrm{~s}, S D=3.1 \mathrm{~s})$ than the acceptance group $(M=5.9 \mathrm{~s}, S D=$ $3.9 \mathrm{~s})$. No difference in number of individuals reporting spinal tenderness presence was identified among the groups, $\chi 2(2, N=74)=2.71, p \geq .25$.

Average pain ratings at baseline were similar across groups, $F(2,73)=.32, p=.73, \eta^{2}=.01$, although there was a multivariate effect for the individual physical tasks, Wilks' $\lambda=.54, F(14,126)=3.09$, $p \leq .001, \eta^{2}=.26$. Follow-up analyses, however, failed to indicate any significant effects at the PII total score or individual item level. Table 3 displays means and standard deviations and Appendix E lists specific follow-up information.

\section{Physical Impairment}

Based on findings that indicated the pre-existing differences among groups on certain measures of physical impairment, the primary analyses controlled for baseline PII performance in a univariate analyses of covariance (ANCOVA) for PII total score and a multivariate analysis of covariance (MANCOVA) for the individual tasks on the PII. Additionally, the analyses with raw change scores continued to be utilized. Univariate and multivariate analyses again were used for the total change in PII and individual tasks, respectively.

There was a significant overall effect of group membership on PII total score after controlling for baseline performance, $F(2,70)=12.02, p \leq .0001, \eta^{2}=.26$. Follow-up comparisons revealed that the estimated marginal means were significantly lower for the acceptance group $(M=3.82, S D=.16)$ than either the pain control $(M=4.97, S D=.17)$ or no change group $(M=4.42, S D=.17)$, with the latter two groups not statistically different from one another. The results of the change score analyses generally mirrored those of the ANCOVA, $F(2,73)=12.43, p \leq .001, \eta^{2}=.26$, with the acceptance group showing greater improvements in physical impairment $(M$ change $=-.78, S D=.91)$ relative to the other groups (pain control: $M$ change $=+.39, S D=.84$; no change: $M$ change $=+.08, S D=.70$ ), which again did not differ from one another. These trends are depicted in Figure 1 and translate into a $16.3 \%$ reduction in 
overall physical impairment for the acceptance group, an $8.3 \%$ worsening for those receiving the pain control instructions, and a $2.5 \%$ decline for the no change group.

After controlling for baseline performance, there was a significant multivariate effect of group membership at the level of the PII individual tasks, Wilks' $\lambda=.69, F(14,130)=1.90, p \leq .05, \eta^{2}=.17$. See Table 4 for descriptive information. Follow-up analyses (see Appendix F) reached significance only for lateral flexion, $F(2,73)=3.46, p<.05, \eta^{2}=.09$. Pairwise comparisons for lateral flexion, however, did not indicate any significant differences. With regard to raw change scores on the PII items, significant differences again were indicated among the groups, Wilks' $\lambda=.68, F(14,130)=2.00, p \leq .05, \eta^{2}=.18$. Significant differences in lateral flexion change were apparent, $F(2,73)=4.19, p \leq .05, \eta^{2}=.11$, with significantly smaller changes occurring in the no change group $(M$ change $=+1.6$ degrees, $S D=3.4$ degrees) compared to the acceptance group ( $M$ change $=+4.7$ degrees, $S D=4.1$ degrees). The pain control group ( $M$ change $=+2.1$ degrees, $S D=4.8$ degrees) did not differ significantly from either of the other groups. See Table 5 for descriptive change score data and Appendix G for all follow-up ANOVAs.

A chi-square analysis of spinal tenderness indicated no group differences for either of the PII trials: baseline, $\chi 2(2, N=74)=2.71, p \geq .25$; post-instructions, $\chi 2(2, N=74)=1.00, p \geq .60$. It also is significant to note that the majority of participants endorsed the presence of spinal tenderness with $95.5 \%$ $(N=67)$ reporting tenderness at baseline and $87.8 \%(N=65)$ during the second assessment.

\section{Pain Ratings}

In order to maintain consistency in analyses, the method used to analyze physical impairment was applied to pain ratings. Pain levels were averaged across all the items to achieve an overall index of pain intensity. Results indicated that pain intensity during the second assessment (see Table 6) was statistically equivalent across all groups after controlling for baseline pain, $F(2,70)=1.59, p=.21, \eta^{2}=$ .04. Analyses of raw change score differences in average pain (see Table 7) similarly were nonsignificant, $F(2,73)=1.76, p=.18, \eta^{2}=.05$.

The MANCOVA for pain ratings on individual PII tasks was significant, Wilks' $\lambda=.59, F(14,126)$ $=2.70, p \leq .005, \eta^{2}=.23$, with significant group differences in pain ratings for active straight leg raise only, $F(2,73)=3.23, p \leq .05, \eta^{2}=.09$. Pairwise comparisons, however, did not indicate any between group differences. Estimated marginal means are displayed in Table 6 and detailed ANCOVA information 
in Appendix $\mathrm{H}$. The multivariate evaluation of differences in pain rating changes from baseline also indicated a significant effect, Wilks' $\lambda=.63, F(14,126)=2.31, p \leq .01, \eta^{2}=.20$, with group differences in active straight leg raise again indicated. The pain control group reported greater increases in pain $(M=$ $.67, S D=1.49)$ compared with the no change group $(M=-.48, S D=.96)$. The acceptance group was not significantly different from either group $(M=-.08, S D=1.51)$. No other pairwise differences reached significance. See Table 7 and Appendix I for descriptive and follow-up ANOVA information, respectively.

\section{Follow-up Questionnaire}

All participants reported that they understood the instructional sets. The majority $(70.3 \%)$ affirmed that the instructions had changed their thinking about the PII tasks. The proportion of individuals indicating this finding was statistically equivalent among the groups, $\chi 2(2, N=74)=.22, p \geq .89$, with $69.2 \%$ in the acceptance, $73.9 \%$ in the pain control, and $68.0 \%$ in the no changes reporting positive effects. A MANOVA performed on the final three questions concerning the utility of the instructional sets, as well as their effect on thinking and task performance, indicated significance, Wilks' $\lambda=.80, F(6,138)=$

2.67, $p \leq .05, \eta^{2}=.10$, with ratings of utility of the instructional sets falling just short of significance, $F(2$, 73) $=2.59, p=.08, \eta^{2}=.07$. Pairwise follow-ups indicated that the acceptance group found the instructions to be of greater utility $(M=6.0, S D=2.1)$ compared with the pain control group $(M=4.5, S D$ = 2.7). Additional means and SDs are located in Table 8. See Appendix $J$ for additional follow-up ANOVA data.

\section{Correlational Analyses}

Correlations among baseline PII ratings and self-report measures are displayed in Table 9. The CPAQ was unrelated with any PII values at baseline, although significant correlations were observed among the other self-report measures and the PII. Given the nature of the present analyses to specifically examine the role of acceptance in physical functioning and the lack of association among the CPAQ and PII variables, additional regression analyses were not performed. As an additional analysis, correlations among the self-report measures were performed. In this case, the CPAQ was significantly related to all self-report measures, $r$ range $=-.38$ to -.53 , all $p$ 's $\leq .001$, with the exception of the FPQ-SF, $r=-.09, p>$ .05 . 


\section{Discussion}

The primary purpose of the present study was to investigate the role of different instructional sets, one encouraging acceptance and the other pain control, on overt physical behavior. A group receiving instructions to not alter behavior on the second PII assessment served to assess for practice effects. A secondary purpose was to assess self-reported pain rating differences among the three groups. Finally, the relation of physical impairment to baseline levels of self-reported acceptance, as well as other psychosocial constructs relevant to chronic pain, was investigated. The study utilized a standardized measure of physical impairment along with three different instructional sets requesting participants to base their behavior on the tasks from a certain perspective. In sum, 74 individuals presenting for treatment evaluation at a multidisciplinary chronic pain treatment center completed the experimental procedure in its entirety.

Individuals assigned to the acceptance group exhibited lower levels of physical impairment relative to those in either of the other two groups after baseline PII performance was statistically controlled. Further, the acceptance group evidenced greater change in PII total score than individuals assigned to either of the other groups. The $16.3 \%$ improvement in overall physical impairment for the acceptance group compares favorably with the changes observed in the pain control group, whose impairment scores worsened by $8.3 \%$. As expected, scores for the no change group stayed fairly stable, with only a $2.5 \%$ decrease in total performance. The general lack of findings across the individual tasks of the PII and significant findings for total scores is consistent with previous literature indicating the reliability of the total score relative to the individual tasks (Fritz \& Riva, 2003), as well as psychometric theory supporting the utility of total scores over individual items (Nunnally \& Bernstein, 1994). The individual tasks on the PII that were significantly different among the groups were lateral flexion performance and pain ratings for the active straight leg raise. It may be that these two tasks differed due to the fact that they are not widely used measures of performance across the majority of physical therapy assessments (Waddell et al., 1992). Therefore, these participants, who by the nature of their longstanding pain and likely repeated prior assessments, may have been more naïve to these specific tasks.

One of the primary theoretical tenants of acceptance is the assumption that negative thoughts, feelings and sensations do not have to directly effect overt behaviors (Hayes, Strosahl et al., 1999). For 
individuals with chronic pain, complaints of pain often are identified as the primary reason for decreases in functioning; contemporary models of chronic pain identify often inaccurate beliefs that increased activity will lead to increased pain as one of the primary causes of pain-related disability (Lethem et al., 1992; Vlayeen \& Linton, 2000). Within the present experiment, pain ratings among the groups were generally not significantly different, thus the acceptance group did more, but hurt the same as the other two groups. Therefore, pain intensity, in and of itself, may not be the primary determinant of functioning. This finding suggests that treatments solely working for pain reduction may not lead to functional improvements. Instead, effective interventions may best be targeted directly at activity level and patient-identified values and goals. These conclusions await empirical investigation.

At a fundamental level, acceptance-based interventions for chronic pain focus on the impact that pain has on one's life, rather than on pain intensity. For individuals who do not respond to traditional pain management interventions by improving function, this difference can be crucial, especially given that perceptions of control over the effects of pain are more strongly associated with self-reported functioning than perceptions of control over pain itself (Tan, Jensen, Robinson-Whelen, Thornby, \& Monga, 2002). Repeated failures to control pain are associated with increased distress and physiological activity (Janssen et al., 2004). These results provide preliminary data that strict efforts to control pain can adversely impact overt behavioral variables as well. When combined with existing data on the difficulty of suppressing acutely painful sensations (Cioffi \& Hollaway, 1993; Sullivan et al., 1997), the conclusion presents itself that this style of coping might best be avoided by those suffering from chronic pain. Given that a significant number of interventions continue to focus on pain control as the foremost treatment goal (e.g., spinal cord stimulators, implantable pumps), a shift in treatment approach seems necessary. It is hoped that the acceptance-based treatments, with their focus on functioning, can assist in this shift and contribute effective modalities. The present experiment provides initial support for acceptance-based interventions in chronic pain and provides a basic foundation upon which to base more intensive, and directly applicable, clinical interventions (e.g., Vowles \& Sorrell, 2004).

The finding that trait levels of acceptance were not reliably related to physical impairment was unexpected. Theoretically, acceptance of chronic pain is hypothesized to be strongly related to measures of physical functioning, given its inherent functional underpinnings. It may be that the measure of physical 
impairment selected for the present study, which primarily measures movement, is not directly generalizable to activities of daily living or activities valued by the participants, which comprise the majority of item content of the CPAQ. Thus, a more direct measure of functioning, perhaps related to occupational or recreational activities, may be more related to baseline levels of acceptance. Further, there could have been some unassessed variable among the present sample that differed significantly from samples utilized in past studies of acceptance in chronic pain which included patients residing in both the United States of America and the United Kingdom (McCracken, 1998; 1999; McCracken \& Eccleston, 2003; McCracken, Eccleston, \& Bell, in press; McCracken, Vowles et al., 2004). Of course, there is a distinctive lack of standardized measures of physical impairment or functioning (Waddell et al., 1992), which serves to complicate the issue. The CPAQ was found to be significantly correlated with the majority of the self-report instruments administered to participants. These results replicate those reported in other published studies using the CPAQ in chronic pain samples (McCracken, 1998; McCracken, Vowles et al., 2004). The lack of association found in this investigation among self-reported acceptance and overt behavioral performance will require follow-up studies to determine whether acceptance is indeed unrelated to physical functioning or whether the finding is an artifact of the present analyses.

As with most investigations, there are a number of limitations and unanswered questions that remain. First, and perhaps most significantly, these data were obtained in a contrived, albeit clinical, experimental setting, which inherently decreases external validity. In addition, baseline differences in physical impairment among the groups is problematic. Because the no change group was generally less physically impaired than the other two groups, they had less room to improve following the instructional sets (i.e., a ceiling effect). Additionally, improvements in physical impairment were observed over the short-term. Thus, the longevity of effects or generalization to other physical activities can be debated and it is unlikely that the audiotaped instructions brought about any lasting effect in functioning. Longer term, more intensive interventions are clearly required to assess the veracity of the present preliminary findings. Furthermore, recent data suggest that exposure to one type of physical activity improves performance on that activity, but has limited generalization to other, dissimilar, movements in low back pain patients (Crombez et al., 2002). The inclusion of more functional tasks, perhaps directly related to specific and individually-tailored values and goals, may have improved generalizability. General stretching and 
exercising may be particularly important, as they appear to produce both short and long-term positive effects (Liddle, Baxter, \& Gracey, 2004).

The present study is the first to actively attempt to modify task performance in a sample of chronic pain patients by using an acceptance-based paradigm. Although the intervention was fairly simple in that it consisted of only a 120-second instructional set, significant effects still were observed. These results extend the body of literature regarding acceptance and chronic pain (reviewed by McCracken, Carson, Eccleston, \& Keefe, 2004) beyond solely self-reported relations and single time-point measurements. Furthermore, it is noteworthy that any changes in physical impairment occurred given that the sample consisted of chronic low back pain patients, who generally are considered to be one of the more difficult and resistant populations to successfully treat (Ofman et al., 2004). In sum, it appears that in chronic low back pain patients, approaching physical tasks from a perspective emphasizing engagement in activity rather than pain minimization, are more adaptive with regard to task performance, at least over the short term.

Individuals with chronic pain typically assume that increased activity will lead to increased pain or injury and these fears are the primary contributor to pain-related distress and disability (Vlaeyen \& Linton, 2000). Disproving these beliefs, therefore, can be viewed as one of the primary goals of pain treatments. This objective is especially important given that stimuli perceived to be the worst have the largest impact on increasing distress behaviors (Vowles, McNeil, Sorrell, \& Lawrence, in press) and the overlap in the symptoms of anxiety and pain (Gross \& Collins, 1981), which complicates patients' ability to discern one from the other. This small scale intervention provides a preliminary method of disproving some of these fears; by encouraging a focus on behavioral activities rather than pain minimization, performance can be improved. In theory, this increase in performance will allow increased contact with positive aspects of daily living and a subsequent decrease in pain-related suffering. Of course, the contrived and short-term nature of the present study precluded the assessment of these long-term effects, and it is likely that more intensive treatment would be required to achieve them. Future studies and clinical interventions can improve on our methods and designs to further illuminate the role of acceptance in decreasing the suffering that is associated with persistent and severe pain. 


\section{References}

Anderson, C. M., Hawkins, R. P., \& Scotti, J. R. (1997). Private events in behavior analysis: Conceptual basis and clinical relevance. Behavior Therapy, 28, 157-179.

Arnoff, G. M. (1991). Chronic pain and the disability epidemic. The Clinical Journal of Pain, 7, 330-338.

Arnoff, G. M., \& McAlary, P. W. (1992). Pain centers: Treatment for intractable suffering and disability resulting from chronic pain. In G. M. Aronoff (Ed.), Evaluation and treatment of chronic pain (pp. 416-449). Baltimore, MD: Williams \& Wilkins.

Bach, P., \& Hayes, S. C. (2002). The use of Acceptance and Commitment Therapy to prevent the rehospitalization of psychotic patients: A randomized controlled trial. Journal of Consulting and Clinical Psychology, 70, 1129-1139.

Baer, R. A. (2003). Mindfulness training as a clinical intervention: A conceptual and empirical review. Clinical Psychology: Science and Practice, 10, 125-143.

Baum, W. M. (1994). Understanding behaviorism: Science, behavior, and culture. New York: HarperCollins.

Batten, S. V., \& Hayes, S. C. (in press). Acceptance and Commitment Therapy in the treatment of comorbid substance abuse and posttraumatic stress disorder: A case study. Clinical Case Studies.

Beck, A. T., Steer, R. A., Brown, G. K. (1996). BDI-II: Beck Depression Inventory manual. 2nd ed. Boston: Harcourt.

Beck, A. T., Steer, R. A., \& Garbin, M. (1988). Psychometric properties of the Beck Depression Inventory: Twenty-five years of evaluation. Clinical Psychology Review, 8, 77-100.

Bendix, T., Bendix, A., Labriola, M., Haestrup, C., \& Ebbehoj, N. (2000). Functional restoration versus outpatient physical training in chronic low back pain: A randomized comparative study. Spine, 25, 2494-2500.

Bengtson, A., Herlitz, J., Karlsson, T., \& Hjalmarson, A. (1996). Distress correlates with the degree of chest pain: A description of patients awaiting revascularisation. Heart, 75, 257-260.

Boeschen, L. E., Koss, M. P., Figueredo, A. J., \& Coan, J. A. (2001). Experiential avoidance and post-traumatic stress disorder: A cognitive mediational model of rape recovery. Journal of Aggression, Maltreatment, and Trauma, 4, 211-245. 
Carter, L. E., McNeil, D. W., Vowles, K. E., Sorrell, J. T., Turk, C., Ries, B., et al. (2002). Effects of emotion on pain reports, tolerance and physiology. Pain Research and Management, 7, 21-30.

Cioffi, D., \& Holloway, J. (1993). Delayed costs of suppressed pain. Journal of Personality and Social Psychology, 64, 274-282.

Cooper, M. L., Russel, M., Skinner, J. B., Frone, M. R., \& Mudar, P. (1992). Stress and alcohol use: Moderating effects of gender, coping, and alcohol expectancies. Journal of Abnormal Psychology, 101, 139-152.

Crombez, G., Eccleston, C., Vlaeyen, J. W. S., Vansteenwegen, D., Lysens, R., \& Eelen, P. (2002). Exposure to physical movements in low back pain patients: Restricted effects of generalization. Health Psychology, 21,573-578.

Crombez, G., Vervaet, L., Lysens, R., Baeyens, F., \& Eelen, P. (1998). Avoidance and confrontation of painful, back-straining movements in chronic back pain patients. Behavior Modification, 62-77.

DeGenova, M. K., Patton, D. M., Jurich, J. A. \& MacDermid, S. M. (1994). Ways of coping among HIVinfected individuals. Journal of Social Psychology, 134, 770-781.

Deyo, R. A. (1983). Conservative therapy for low back pain: Distinguishing useful from useless therapy. Journal of the American Medical Association, 250, 1057-1062.

Deyo, R. A., Nachemson, A., \& Mirza, S. K. (2004). Spinal-fusion surgery: The case for restraint. The New England Journal of Medicine, 350, 722-726.

Dougher, M. J. (Ed.). (2002). Clinical behavior analysis. Reno, NV: Context Press.

Dougher, M. J., \& Hackbert, L. (1994). A behavior-analytic account of depression and a case report using acceptance-based procedures. The Behavior Analyst, 17, 321-334.

Eifert, G. H., \& Heffner, M. (2003). The effects of acceptance versus control contexts on avoidance of panic-related symptoms. Journal of Behavior Therapy and Experimental Psychiatry, 34, 293-312.

Elliott, A. M., Smith, B. H., Hannaford, P. C., Smith, W. C., \& Chambers, W. A. (2002). The course of chronic pain in the community: Results of a 4-year follow-up study. Pain, 99, 299-307.

Feldner, M. T., Zvolensky, M. J., Eifert, G. H., \& Spira, A. P. (2003). Emotional avoidance: An experimental test of individual differences and response suppression using biological challenge. Behaviour Research and Therapy, 41, 403-411. 
Fishbain, D. A., Cutler, R., Rosomoff, H. L., \& Rosomoff, R. S. (1997). Chronic pain-associated depression: Antecedent or consequence of chronic pain? A review. The Clinical Journal of Pain, 13, 116-137.

Fishbain, D. A., Rosomoff, H. L., Goldberg, M., Cutler, R., Abdel-Moty, Khalil, T., \& Rosomoff, R. S. (1993). The prediction of return to the workplace after multidisciplinary pain center treatment. The Clinical Journal of Pain, 9, 3-15.

Flor, H., Knost, B., Birbaumer, N. (2002). The role of operant conditioning in chronic pain: An experimental investigation. Pain, 95, 111-118.

Fordyce, W. E. (1976). Behavioral methods for chronic pain and illness. St. Louis, MO: C. V. Mosby.

Friedrich, M., Gittler, G., Halberstadt, Y., Cermak, T., \& Heiller, I. (1998). Combined exercise and motivation program: Effect on the compliance and level of disability of patients with chronic low back pain: A randomized controlled trial. Archives of Physical Medicine and Rehabilitation, 79, 475-487.

Fritz, J. M., \& Piva, S. R. (2003). Physical Impairment Index: Reliability, validity, and responsiveness in patients with acute low back pain. Spine, 28, 1189-1194.

Gatchel, R. J. (1996). Psychological disorders and chronic pain: Cause-and-effect relationships. In R. J. Gatchel \& D. C. Turk (Eds.), Psychological approaches to pain management: A practitioner's handbook (pp. 33-54). New York: Guilford.

Gatchel, R. J. (1999). Perspectives on pain: A historical overview. In R. J. Gatchel \& D. C. Turk (Eds.) Psychosocial factors in pain: Critical perspectives (pp. 3-17). New York: Guilford.

Geiser, D. S. (1992). A comparison of acceptance-focused and control-focused psychological treatments in a chronic pain treatment center. Unpublished doctoral dissertation, University of Nevada, Reno.

Geisser, M. E., Robinson, M. E., \& Henson, C. D. (1994). The Coping Strategies Questionnaire and chronic pain adjustment: A conceptual and empirical reanalysis. The Clinical Journal of Pain, 10, 98-106.

Goubert, L., Crombez, G., Eccleston, C., \& Devulder, J. (2004). Distraction from chronic pain during a pain-inducing activity is associated with greater post-activity pain. Pain, 110, 220-227. 
Griest, J. H., Marks, I. M., Berlin, F., Gournay, K., \& Noshirvani, H. (1980). Avoidance versus confrontation of fear. Behavior Therapy, 11, 1-14.

Gross, R. T., \& Collins, F. L., Jr. (1981). On the relationship between anxiety and pain: A methodological confounding. Clinical Psychology Review, 1, 375-386.

Harden, R. N. (2002). Chronic opioid therapy: Another reappraisal. American Pain Society Bulletin, 12, 8-12.

Hayes, S. C. (1994). Content, context, and types of acceptance. In S. C. Hayes, N. S. Jacobson, V. M. Follette, \& M. J. Dougher (Eds.), Acceptance and change: Content and context in psychotherapy (pp. 13-32). Reno, NV: Context Press.

Hayes, S. C., Bissett, R. T., Korn, Z., Zettle, R. D., Rosenfarb, I. S., Cooper, L. D., et al. (1999). The impact of acceptance versus control rationales on pain tolerance. Psychological Record, 49, 33-47.

Hayes, S. C., Jacobson, N. S., Follette, V. M., \& Dougher, M. J. (Eds.) (1994). Acceptance and change: Content and context in psychotherapy. Reno, NV: Context Press.

Hayes, S. C., Strosahl, K., \& Wilson, K. G. (1999). Acceptance and Commitment Therapy: An experiential approach to behavior change. New York: Guilford.

Hayes, S. C., Wilson, K. G., Gifford, E. V., Folette, V. M., \& Strosahl, K. (1996). Experiential avoidance and behavioral disorders: A functional dimensional approach to diagnosis and treatment. Journal of Consulting and Clinical Psychology, 64, 1152-1168.

Hazard, R. G. (1991). Functional restoration treatment outcomes. In T. G. Mayer, V. Mooney, \& R. J. Gatchel (Eds.), Contemporary conservative care for painful spinal disorders (pp. 482-487). Malvern, PA: Lea \& Febiger.

Heffner, M., Sperry, J. A., Eifert, G. H., \& Detweiler, M. (2002). Acceptance and Commitment Therapy in the treatment of an adolescent female with anorexia nervosa: A case example. Cognitive and Behavioral Practice, 9, 232-236.

Hildebrandt, J., Pfingsten, M., Saur, P., \& Jansen, J. (1997). Prediction of success from a multidisciplinary treatment program for chronic low back pain. Spine, 22, 990-1001. 
Jacobson, N. S., Christensen, A., Prince, S. E., Cordova, J., \& Eldridge, K. (2000). Integrative behavioral couple therapy: An acceptance-based, promising new treatment for couple discord. Journal of Consulting and Clinical Psychology, 68, 321-355.

Jamison, R. N., Anderson, K. O., Peeters-Asdourian, C., \& Ferrante, F. M. (1994). Survey of opioid use in chronic nonmalignant pain patients. Regional Anesthesia, 19, 225-230.

Janssen, S. A., Spinhoven, P., Arntz, A. (2004). The effects of failing to control pain: an experimental investigation. Pain, 107, 227 - 233.

Jensen, M. P., \& Karoly, P. (2001). Self-report scales and procedures for assessing pain in adults. In Turk DC, Melzack R. (Eds.), Handbook of pain assessment ( $2^{\text {nd }}$ edition; pp. 15-34). New York: Guilford.

Jensen, M. P., Turner, J. A., \& Romano, J. M. (1991). Coping with chronic pain: A critical review of the literature. Pain, 47, 249-283.

Jolliffe, C. D., \& Nicholas, M. K. (2004). Verbally reinforcing pain reports: An experimental test of the operant model of chronic pain. Pain, 107, 167-175.

Kabat-Zinn, J. (2003). Mindfulness-based interventions in context: Past, present, and future. Clinical Psychology: Science and Practice, 10, 144 - 156.

Keefe, F. J., Lumley, M., Anderson, T., Lynch, T., \& Carson, K. L. (2001). Pain and emotion: New research directions. Journal of Clinical Psychology, 57, 587-607.

Kemler, M. A., Barendse, G. A. M., Van Kleef, M., De Vet, H. C. W., Rijks, C. P. M., Furnee, C. A., et al. (2000). Spinal cord stimulation in patients with chronic reflex sympathetic dystrophy. New England Journal of Medicine, 343, 618-624.

Kennedy, S. G., McNeil, D. W, Hursey, K. G., Vowles, K. E., Sorrell, J. T., Lawrence, S. M., et al. (2001, November). Development of a short form of the fear of pain questionnaire. Poster presented at the meeting of the Association for the Advancement of Behavior Therapy, Philadelphia, PA.

Kori, S. H., Miller, R. P., \& Todd, D. D. (1990). Kinisophobia: A new view of chronic pain behavior. Pain Management, 3, 35-43.

Koster, E. H. W., Rassin, E., Crombez, G., \& Naring, G. W. B. (2003). The paradoxical effects of 
suppressing anxious thoughts during imminent threat. Behaviour Research and Therapy, 41, 1113-1120.

Krause, S. J., Weiner, R. L., \& Tait, R. C. (1994). Depression and pain behavior in patients with chronic pain. The Clinical Journal of Pain, 10, 122-127.

Lethem, J., Slade, P. D., Troup, J. D. G., \& Bentley, G. (1983) Outline of a fear-avoidance model of exaggerated pain perception - I. Behaviour Research and Therapy, 21, 401-408.

Li, L., \& Moore, D. (1998). Acceptance of disability and its correlates. Journal of Social Psychology, 138, 13-25.Liddle, S. D., Baxter, G. D., \& Gracey, J. H. (2004). Exercise and chronic low back pain: What works?

Pain, 107, 176-190.

Linehan, M. M. (1993). Cognitive-behavioral treatment of borderline personality disorder. New York: Guilford Press.

Linehan, M. M., Schmidt, H., Dimeff, L. A., Craft, J. C., Kanter, J., \& Comtois, K. A. (1999). Dialectical behavior therapy for patients with borderline personality disorder and drug dependence. American Journal on Addictions, 8, 279-292.

Linkowski, D. C. (1971). A scale to measure acceptance of disability. Rehabilitation Counseling Bulletin, 4, 236-244.

Linscott, J., \& DiGiuseppe, R. (1998). Cognitive assessment. In A. S. Bellack, \& M. Hernsen (Eds.), Behavioral assessment: A practical handbook. Needham Heights, MA: Allyn \& Bacon.

Marcks, B. A. \& Woods, D. W. (in press). A comparison of thought suppression to an acceptance-based technique in the management of personal intrusive thoughts: A controlled evaluation. Behaviour Research and Therapy.

McCracken, L. M. (1998). Learning to live with the pain: Acceptance of pain predicts adjustment in persons with chronic pain. Pain, 74, 21-27.

McCracken, L. M. (1999). Behavioral constituents of chronic pain acceptance: Results from factor analysis of the Chronic Pain Acceptance Questionnaire. Journal of Back and Musculosketal Rehabilitation, 13, 93-100.

McCracken, L. M., Carson, J. W., Eccleston, C., \& Keefe, F. J. (2004). Acceptance and change in the 
context of chronic pain. Pain, 109, 4-7.

McCracken, L. M., \& Dhingra, L. (2002). A short version of the Pain Anxiety Symptoms Scale (PASS-20): Preliminary development and validity. Pain Research and Management, 7, 45-50.

McCracken, L. M., \& Eccleston, C. (2003). Coping or acceptance: What to do about chronic pain? Pain, $105,197-204$.

McCracken, L. M., Eccleston, C., \& Bell, L. (in press). Clinical assessment of behavioral coping responses: Preliminary results from a brief inventory. European Journal of Pain.

McCracken, L. M., Faber, S. D., \& Janeck, A. S. (1998). Pain-related anxiety predicts non-specific physical complaints in persons with chronic pain. Behaviour Research and Therapy, 36, 621630.

McCracken, L. M , Gross, R. T., \& Eccleston, C. (2002). Multimethod assessment of treatment process in chronic low back pain: Comparison of reported pain-related anxiety with directly measured physical capacity. Behaviour Research and Therapy, 40, 585-594.

McCracken, L. M., Spertus, I. L., Janeck, A. S., Sinclair, D. F., \& Wetzel, T. (1999). Behavioral dimensions of adjustment in persons with chronic pain: Pain-related anxiety and acceptance. Pain, 80, 283-289.

McCracken, L. M., Vowles, K. E., \& Eccleston, C. (2004). Acceptance of chronic pain: Component analysis and a revised assessment method. Pain, 107, 159-166.

McCracken, L. M., Zayfert, C., \& Gross, R. T. (1992). The Pain Anxiety Symptoms Scale: Development and validation of a scale to measure fear of pain. Pain, 50, 67-73.

McMain, S., Korman, L. M., \& Dimeff, L. (2001). Dialectical behavior therapy and the treatment of emotion dysregulation. Journal of Clinical Psychology, 57, 183-196.

McNeil, D. W., \& Rainwater, A. J., III. (1998). Development of the Fear of Pain Questionnaire - III. Journal of Behavioral Medicine, 21, 389-410.

McNeil, D. W., \& Vowles, K. E. (2004). Assessment of fear and anxiety associated with pain: Conceptualization, methods, and measures. In G. J. G. Asmundson, J. W. S. Vlaeyen, \& G. Crombez (Eds.), Understanding and treating fear of pain (pp. 189-211). Oxford, United Kingdom: Oxford University Press. 
Melzack, R. (1987). The short form McGill Questionnaire. Pain, 30, 191-197.

Melzack, R., Katz, J. (1992). The McGill Pain Questionnaire: Appraisal and current status. In: Turk DC, Melzack R (Eds.), Handbook of pain assessment (pp. 152-166). New York: Guilford.

Melzack, R., Katz, J. (2001). The McGill Pain Questionnaire: Appraisal and current status. In Turk DC, Melzack R (Eds.), Handbook of pain assessment ( $2^{\text {nd }}$ edition; pp. 35-52). New York: Guilford.

Nunnally, J. C., \& Bernstein, I. H. (1994). Psychometric theory. New York: McGraw-Hill.

Ofman, J. J., Badamgarav, E., Henning, J. M., Knight, K., Gano, A. D., Levan, R. K. et al. (2004). Does disease management improve clinical and economic outcomes in patients with chronic diseases? A systematic review. American Journal of Medicine, 117, 182-92.

Penny, K. I., Purves, A. M., Smith, B. H., Chambers, W. A., \& Smith, W. C. (1999). Relationship between the chronic pain grade and measures of physical, social, and psychological well-being. Pain, 79, 275-279.

Phillips, H. C. (1987). Avoidance behaviour and its role in sustaining chronic pain. Behaviour Research and Therapy, 25, 273-279.

Rahula, W. (1974). What the Buddha taught. New York: Grove Press.

Rassin, E., Merckelback, H., \& Muris, P. (2000). Paradoxal and less paradoxal effects of thought suppression: A critical review. Clinical Psychology Review, 20, 973-995.

Rethelyi, J. M., Berghammer, R., \& Kopp, M. S. (2001). Comorbidity of pain-associated disability and depressive symptoms in connection with sociodemographic variables: Results from a crosssectional epidemiological survey in Hungary. Pain, 93, 115-121.

Risdon, A., Eccleston, C., Crombez, G., \& McCracken, L. M. (2003). How can we learn to live with pain? A Q-Methodological analysis of the diverse understandings of acceptance of chronic pain. Social Science and Medicine, 56, 375-386.

Robinson, M. E., \& Riley, J. L. (1999). The role of emotion in pain. In R. J. Gatchel \& D. C. Turk (Eds.) Psychosocial factors in pain: Critical perspectives (pp. 74-88). New York: Guilford.

Robinson, P., \& Hayes, S. C. (1999). Acceptance and commitment: A model for integration. In N. A. Cummings, J. L. Cummings, \& J. N. Johnson (Eds.). Behavioral health in primary care: A guide for clinical integration. Madison, CT: Psychosocial Press/International Universities Press, Inc. 
Rosenstiel, A. \& Keefe, F. J. (1983). The use of coping strategies in chronic low back pain patients: Relationship to patient characteristics and current adjustment. Pain, 17,213-622.

Roth, S., \& Cohen, L. J. (1986). Approach, avoidance, and coping with stress. American Psychologist, 41, 813-819.

Sperry-Clark, J. A., McNeil, D. W., \& Ciano-Federoff, L. (1999). Assessing chronic pain patients: The fear of pain questionnaire-III. In L. VandeCreek \& T. L. Jackson (Eds.), Innovations in clinical practice: A source book (vol. 17, pp. 293-305). Sarasota, FL: Professional Resource Press.

Sullivan, M. J., Rouse, D., Bishop, S., \& Johnston, S. (1997). Thought suppression, catastrophizing, and pain. Cognitive Therapy \& Research, 21, 555-568.

Summers, J. D., Rapoff, M. A., Varghese, G., Porter, K., \& Palmer, R. E. (1991). Psychosocial factors in chronic spinal cord injury pain. Pain, 58, 280-282.

Tan, G., Jensen, M. P., Robinson-Whelen, S., Thornby, J. I., \& Monga, T. (2002). Measuring control appraisals in chronic pain. Journal of Pain, 3, 385-393

Teasdale, J. D., Segal, Z. V., Williams, J. M. G., Ridgeway, V. A., Soulsby, J. M., \& Lau, M. A. (2000). Prevention of relapse/recurrence in major depression by mindfulness-based cognitive therapy. Journal of Consulting and Clinical Psychology, 68, 615-623.

Turk, D. C. (1990). Customizing treatment for chronic pain patients: Who, what, why? Clinical Journal of Pain, 6, 255-270.

Turk, D. C. (1996). Biopsychosocial perspective on chronic pain. In R. J. Gatchel \& D. C. Turk (Eds.) Psychological approaches to pain management: A practitioner's handbook (pp. 3-32). New York: Guilford.

Turk, D. C., Okifuji, A., \& Scharff, L. (1995). Chronic pain and depression: Role of perceived impact and perceived control in different age cohorts. Pain, 61, 93-101.

Viane, I., Crombez, G., Eccleston, C., Poppe, C., Devulder, J., Van Houdenhove, B., \& De Corte, W. (2003). Acceptance of pain is an independent predictor of mental well-being in patients with chronic pain: Empirical evidence and reappraisal. Pain, 106, 65-72.

Vlaeyen, J. W. S., \& Linton, S. J. (2000). Fear-avoidance and its consequences in chronic musculoskeletal pain: A state of the art. Pain, 85, 317-332. 
Vlaeyen, J. W. S., \& Morley, S. (2004). Active despite pain: The putative role of stop-rules and current mood. Pain, 110, 512-516.

Vowles, K. E., \& Gross, R. T. (2003). Work-related beliefs about injury and physical capability for work in individuals with chronic pain. Pain, 101, 291-298.

Vowles, K. E., \& Gross, R. T., \& Sorrell, J. T. (2004). Predicting work status following interdisciplinary treatment for chronic pain. European Journal of Pain, 8, 351-358.

Vowles, K. E., McNeil, D. W., Sorrell, J. T., \& Lawrence, S. A. (in press). Fear and pain: Investigating the interaction between two aversive states. Journal of Abnormal Psychology.

Vowles, K. E., \& Sorrell, J. T. (2004, May). Acceptance of chronic pain: A short-term group intervention. Poster presented at the 2004 meeting of the American Pain Society/Canadian Pain Society, Vancouver, British Columbia, Canada

Vowles, K. E., Zvolensky, M. J., Gross, R. T., \& Sperry, J. A. (2004). Pain-related anxiety in the prediction of chronic low-back pain distress. Journal of Behavioral Medicine, 27, 77-89.

Waddell, G. (1987). A new clinical model for the treatment of low-back pain. Spine, 12, 632-644.

Waddell, G., Feder, G., \& Lewis, M. (1997). Systematic reviews of bed rest and advice to stay active for acute low back pain. British Journal of General Practice, 47, 647-652.

Waddell, G., Somerville, D., Henderson, I., \& Newton, M. (1992). Objective clinical evaluation of physical impairment in chronic low back pain. Spine, 17, 617-628.

Walsh, R. (1980). The consciousness disciplines and the behavioral sciences: Questions of comparison and assessment. American Journal of Psychiatry, 137, 663-673.

Watson, P. J., Booker, C. K., Moores, L.,\& Main, C. J. (2004). Returning the chronically unemployed with low back pain to employment. European Journal of Pain, 8, 359-369.

Wegner, D. M. (1994). Ironic processes of mental control. Psychological Review, 101, 34-52.

Wegner, D. M., Schneider, D. J., Carter, S. R., \& White, T. L. (1987). Paradoxical effects of thought suppression. Journal of Personality and Social Psychology, 53, 5-13.

Williams, D. A. (1996). Acute pain management. In R. J. Gatchel \& D. C. Turk (Eds.), Psychological approaches to pain management: A practitioner's handbook (pp. 33-54). New York: Guilford.

Wolpe, J. (1958). Psychotherapy by reciprocal inhibition. Stanford, CA: Stanford University Press 


\section{Appendix A}

Instructional Sets

\section{First Instructions for All Participants}

In the next part of this evaluation, there are stretching, bending, and other activities for you to do with the physical therapist. These activities involve bending your back a few different ways and lifting you legs and shoulders while lying down. While you are doing these activities this time, it is extremely important that you do your best to stretch and bend as far as you can. After each step, you will be asked to rate whether you experienced any pain, on a $0-10$ scale, with 0 being "no pain" and 10 being the "worst pain you've ever experienced."

\section{Second Instructions}

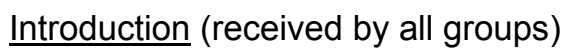

"The research you are participating in today is important because it may allow doctors understand what methods are best in helping people cope with pain that can't be relieved by medicines or surgery or in other ways. Your role participating in this research is extremely valuable, and your time and effort is appreciated. Thank you."

\section{Pain control}

"Now, for the specifics about what you need to do this time. You will do the same stretching, bending, and other activities you just completed. This time, however, it is extremely important that you use a specific strategy to prevent or cope with the pain. Virtually everyone finds that they can do more, like stretching farther or bending longer, for at least a short period of time, if they set their mind to it. The pain is still there, but the person does more because they know that they don't have to keep repeating the activity.

There is a strategy that has been found to be helpful to many people in certain circumstances in preventing or coping with pain in the short-term. This strategy is CONTROL. Specifically, please try to exert control to prevent any pain from occurring, or stopping it from increasing. An example might help to emphasize how CONTROL can help. Think of yourself as a person running a marathon, which is a foot race for 26 Miles. People who run for long distances often report that they experience a lot of pain and (appendix continues) 


\section{Appendix A (con't)}

discomfort while running; they keep running and running in spite of the pain by CONTROLLING it in their minds. Even though it is severe pain, they can CONTROL it because they know that it will stop once the race is over. Please do your best to do the same as marathon runners. Use whatever method you think will work best to CONTROL the pain; just make sure that you are concentrating on pain and on preventing it from occurring or getting worse. CONTROL any pain by preventing it and making every attempt to keep it from increasing during the tasks that you are going to do again now. Remember, CONTROL can work for short periods of time, even if the pain is bad. Use CONTROL to help yourself do your best during these tasks."

\section{Pain acceptance}

"Now, for the specifics about what you need to do this time. You will do the same stretching, bending, and other activities you just completed. This time, however, it is extremely important that you use a specific strategy to prevent or cope with the pain. Virtually everyone finds that they can do more, like stretching farther or bending longer, for at least a short period of time, if they set their mind to it. The pain is still there, but the person does more because they know that they don't have to keep repeating the activity.

There is a strategy that has been found to be helpful to many people in certain circumstances in preventing or coping with pain in the short-term. This strategy is acceptance. Specifically, please try to concentrate on performing the activities themselves and do not let your mind focus on any pain or discomfort. By not fighting the pain, you will be able to spend your energy on the activity itself. An example might help to emphasize how acceptance can help. Think of yourself as a person running a marathon, which is a foot race for 26 Miles. People who run for long distances often report that they experience a lot of pain and discomfort while running; they keep running and running in spite of the pain by ACCEPTING it in their minds and focusing on the race that they are running. Even though it is severe pain, they can ACCEPT it because they know that the pain does not have to effect how they

(appendix continues) 


\section{Appendix A (con't)}

perform. Please do your best to do the same as marathon runners. ACCEPT any pain by focusing on whatever behavior you need to do during the tasks that you are going to do again now. Remember, acceptance can work for short periods of time, even if the pain is bad. Use acceptance to help yourself do your best during these tasks."

\section{No change}

"Now, for the specifics about what you need to do this time. You will do the same stretching, bending, and other activities you just completed. This time, it is again extremely important that you set your mind to prevent or cope with any pain in just the same way you did the first time you performed them. So in the next part of this evaluation, there again are stretching, bending, and other activities for you to do with the physical therapist. These activities involve bending your back a few different ways and lifting you legs and shoulders while lying down. While you are doing these activities this time, it is extremely important that you do your best to stretch and bend as far as you can. You've done them once before already, so this time you already know more about what will happen. There should be no surprises. It will be the same set of activities, just repeated one more time.

An example might help to emphasize what you need to do this time. Think of yourself as a person running a marathon, which is a foot race for 26 Miles. People who run for long distances often report that they experience a lot of pain and discomfort while running; they keep running and running in spite of the pain because they have practiced a way to help them deal with the pain. Before running the marathon, they practice what they are doing and continue to cope with it as they have in the past. This time, when you do the activities, please concentrate on using whatever method you used to cope with the pain the first time and simply use it again. You can think of this as practicing that method. Just do the same thing you did before and just set your mind to prevent or cope with any pain in just the same way you did before."

*NOTE: As indicated in the text, the following references were utilized in the construction of scripts for the acceptance and pain control groups: Bach \& Hayes, 2002; Eifert \& Heffner, 2003; Geiser, 1992; Hayes, Bissett et al., 1999; McCracken, Eccleston, \& Bell, in press; McCracken, Vowles, \& Eccleston, 2004. 


\section{Appendix B}

Participant Number:

$$
\text { Physical Therapy Follow-up Questionnaire }
$$

1. Did you understand the instructions?

$$
\text { YES NO }
$$

2. Did the instructions change the way you thought about the seven bending and stretching tasks that you were asked to do?

$$
\text { YES NO }
$$

${ }^{* *}$ For the rest of the questions, please make your rating based on the following scale:

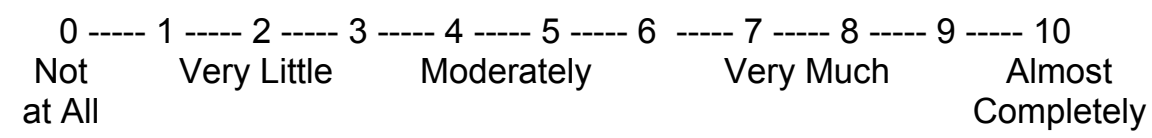

3. Following the second set of instructions, how much did you change the way you thought about how to approach the seven tasks?

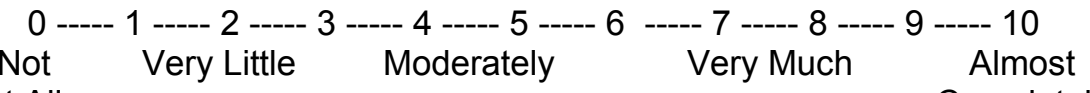

$$
\begin{aligned}
& \text { at All Completely }
\end{aligned}
$$

4. How well were you able to use the strategy that was given during the second set of instructions?

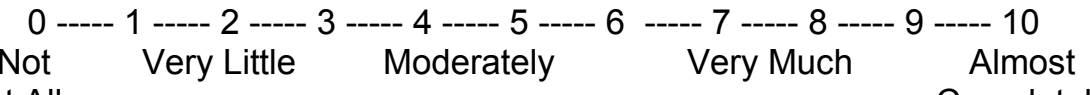

$$
\begin{aligned}
& \text { at All Completely }
\end{aligned}
$$

5. How much did the strategy given in the second set of instructions affect your performance?

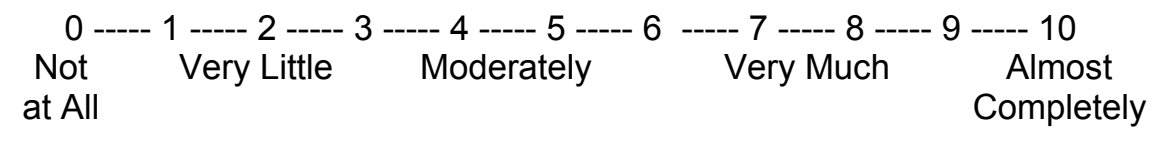

Thank you!! 


\section{Appendix C}

ANOVA Table for Demographic and Self-Report Measures

\begin{tabular}{llll}
\hline Dependent Measure & $d f$ & $F$ & .87 \\
\hline Age & 2 & .14 & .72 \\
Education & 2 & .34 & .11 \\
Beck Depression Inventory & 2 & 2.3 & .10 \\
Chronic Pain Acceptance Questionnaire & 2 & 2.4 & .79 \\
Pain Anxiety Symptoms Scale-20 & 2 & .24 & .75 \\
McGill Pain Questionnaire-Short Form & 2 & .29 & .38 \\
Fear of Pain Questionnaire-Short Form & 2 & .99 & .75 \\
Pain Duration & 2 & .29 & .24 \\
Present Pain & 2 & 1.48 & .14 \\
Average Pain & 2 & 2.00 & .12 \\
Worst Pain & 2 & 2.20 & 1.00 \\
Least Pain & 2 & .002 & .20 \\
Pain-related Surgeries & 2 & 1.63 & .92 \\
Pain Locations & 2 & & .33 \\
Classes of Pain Medications & 2 & & .92 \\
\hline
\end{tabular}




\section{Appendix D}

ANOVA Table for Baseline Physical Impairment Index Scores

\begin{tabular}{lllll}
\hline Dependent Measure & $d f$ & $F$ & $p$ & $\eta^{2}$ \\
\hline Total Score & 2 & 3.52 & .04 & .09 \\
Flexion & 2 & 1.14 & .33 & .03 \\
Extension & 2 & .67 & .52 & .02 \\
Lateral Flexion & 2 & 1.91 & .16 & .05 \\
Straight Leg Raise & 2 & 5.49 & .006 & .13 \\
Active Straight Leg Raise & 2 & 6.40 & .003 & .15 \\
Active Sit-up & 2 & 3.71 & .029 & .10 \\
\end{tabular}




\section{Appendix E}

ANOVA Table for Pain Ratings During Baseline

Completion of the Physical Impairment Index

\begin{tabular}{lllll}
\hline Dependent Measure & $d f$ & $F$ & $p$ & $\eta^{2}$ \\
\hline Total Score & 2 & .34 & .72 & .01 \\
Flexion & 2 & .95 & .39 & .03 \\
Extension & 2 & 1.01 & .37 & .03 \\
Lateral Flexion & 2 & .03 & .97 & .001 \\
Spinal Tenderness & 2 & 1.92 & .15 & .05 \\
Straight Leg Raise & 2 & 3.12 & .051 & .08 \\
Active Straight Leg Raise & 2 & 2.24 & .12 & .06 \\
Active Sit-up & 2 & .79 & .46 & .02 \\
\hline
\end{tabular}




\section{Appendix F}

ANCOVA Table for Physical Impairment Index Subscales and Total Score

\begin{tabular}{lllll}
\hline Dependent Measure & $d f$ & $F$ & $p$ & $\eta^{2}$ \\
\hline Flexion & 2 & 2.86 & .06 & .08 \\
Extension & 2 & 2.69 & .08 & .07 \\
Lateral Flexion & 2 & 3.46 & .04 & .09 \\
Straight Leg Raise & 2 & 1.52 & .23 & .04 \\
Active Straight Leg Raise & 2 & .07 & .93 & .002 \\
Active Sit-up & 2 & .28 & .75 & .01 \\
\hline
\end{tabular}




\section{Appendix G}

ANOVA Table for Change Scores on Physical Impairment Subscales and Total Score

\begin{tabular}{lllll}
\hline Dependent Measure & $d f$ & $F$ & $p$ & $\eta^{2}$ \\
\hline Flexion & 2 & 2.59 & .08 & .07 \\
Extension & 2 & 1.97 & .15 & .05 \\
Lateral Flexion & 2 & 4.19 & .02 & .11 \\
Straight Leg Raise & 2 & 2.15 & .13 & .06 \\
Active Straight Leg Raise & 2 & .19 & .83 & .01 \\
Active Sit-up & 2 & .27 & .76 & .01 \\
\hline
\end{tabular}




\section{Appendix $\mathrm{H}$}

ANCOVA Table for Physical Impairment Index Pain Ratings

\begin{tabular}{lllll}
\hline Dependent Measure & $d f$ & $F$ & $p$ & $\eta^{2}$ \\
\hline Flexion & 2 & .93 & .40 & .03 \\
Extension & 2 & 1.00 & .38 & .03 \\
Lateral Flexion & 2 & .01 & .99 & $\leq .001$ \\
Spinal Tenderness & 2 & 2.12 & .13 & .06 \\
Straight Leg Raise & 2 & 1.72 & .19 & .05 \\
Active Straight Leg Raise & 2 & 3.23 & .05 & .09 \\
Active Sit-up & 2 & 1.25 & .29 & .04 \\
\end{tabular}


Appendix I

ANOVA Table for Change Scores on Physical Impairment Pain Ratings

\begin{tabular}{lllll}
\hline Dependent Measure & $d f$ & $F$ & $p$ & $\eta^{2}$ \\
\hline Flexion & 2 & .133 & .27 & .04 \\
Extension & 2 & 1.19 & .31 & .03 \\
Lateral Flexion & 2 & .34 & .71 & .01 \\
Straight Leg Raise & 2 & 2.73 & .07 & .07 \\
Active Straight Leg Raise & 2 & 4.23 & .02 & .11 \\
Active Sit-up & 2 & 1.06 & .35 & .03 \\
\hline
\end{tabular}




\section{Appendix $\mathrm{J}$}

ANOVA Table for Follow-up Questionnaire Concerning the Instructional Sets

\begin{tabular}{lllll}
\hline Dependent Measure & $d f$ & $F$ & $p$ & $\eta^{2}$ \\
\hline Change in thinking & 2 & 1.02 & .37 & .03 \\
Utility & 2 & 2.59 & .08 & .07 \\
Effect on Performance & 2 & .12 & .89 & .003 \\
\hline
\end{tabular}




\section{Table 1}

Descriptive information for Demographic and Self-Report Measures by Instructional Group

\begin{tabular}{|c|c|c|}
\hline Dependent Measure & Group & Mean $(S D)$ \\
\hline \multirow[t]{3}{*}{ Age (years) } & Acceptance & $38.0(7.8)$ \\
\hline & Pain control & $39.3(6.4)$ \\
\hline & No change & $38.41(0.9)$ \\
\hline \multirow[t]{3}{*}{ Education (years) } & Acceptance & $11.2(1.5)$ \\
\hline & Pain control & $11.7(2.2)$ \\
\hline & No change & $11.2(3.1)$ \\
\hline \multirow[t]{3}{*}{ Beck Depression Inventory } & Acceptance & $30.7(12.6)$ \\
\hline & Pain control & $37.4(10.8)$ \\
\hline & No change & $31.9(10.7)$ \\
\hline \multirow[t]{3}{*}{ Chronic Pain Acceptance Questionnaire } & Acceptance & $33.8(14.6)$ \\
\hline & Pain control & $37.5(15.4)$ \\
\hline & No change & $28.7(10.5)$ \\
\hline \multirow[t]{3}{*}{ Pain Anxiety Symptoms Scale-20 } & Acceptance & $69.3(16.6)$ \\
\hline & Pain control & $66.0(19.0)$ \\
\hline & No change & $67.2(15.1)$ \\
\hline \multirow[t]{3}{*}{ McGill Pain Questionnaire-Short Form } & Acceptance & $25.7(9.0)$ \\
\hline & Pain control & $27.0(7.6)$ \\
\hline & No change & $25.3(6.3)$ \\
\hline \multirow[t]{3}{*}{ Fear of Pain Questionnaire-Short Form } & Acceptance & $24.6(8.6)$ \\
\hline & Pain control & $23.9(6.5)$ \\
\hline & No change & $26.7(6.0)$ \\
\hline \multirow[t]{3}{*}{ Pain Duration (months) } & Acceptance & $22.3(13.4)$ \\
\hline & Pain control & $21.0(16.2)$ \\
\hline & No change & $19.4(10.1)$ \\
\hline
\end{tabular}


Table 1 (con't)

\begin{tabular}{|c|c|c|}
\hline \multirow[t]{3}{*}{ Present Pain } & Acceptance & $6.8(1.9)$ \\
\hline & Pain control & $6.0(1.5)$ \\
\hline & No change & $6.5(1.5)$ \\
\hline \multirow[t]{3}{*}{ Average Pain } & Acceptance & $6.4(2.3)$ \\
\hline & Pain control & $5.3(1.7)$ \\
\hline & No change & $6.0(1.3)$ \\
\hline \multirow[t]{3}{*}{ Worst Pain } & Acceptance & $9.7(0.6)$ \\
\hline & Pain control & $9.2(1.1)$ \\
\hline & No change & $9.6(0.8)$ \\
\hline \multirow[t]{3}{*}{ Least Pain } & Acceptance & $3.6(2.3)$ \\
\hline & Pain control & $3.9(1.5)$ \\
\hline & No change & $3.8(1.3)$ \\
\hline \multirow[t]{3}{*}{ Pain-related Surgeries } & Acceptance & $1.7(0.7)$ \\
\hline & Pain control & $1.6(0.5)$ \\
\hline & No change & $1.9(0.8)$ \\
\hline \multirow[t]{3}{*}{ Pain Locations } & Acceptance & $1.7(0.8)$ \\
\hline & Pain control & $1.6(0.5)$ \\
\hline & No change & $1.9(0.8)$ \\
\hline \multirow[t]{3}{*}{ Classes of Pain Medications } & Acceptance & $1.7(0.8)$ \\
\hline & Pain control & $1.3(0.9)$ \\
\hline & No change & $1.4(0.8)$ \\
\hline
\end{tabular}

Note: $\mathrm{N}=74 ;$ Acceptance: $\mathrm{n}=26$; Pain control: $\mathrm{n}=23$; No change: $\mathrm{n}=25$. 
Table 2

Mean (Standard Deviation) Values for the Physical Impairment Index

\begin{tabular}{|c|c|c|c|}
\hline & Group & Baseline & Post-Instructions \\
\hline \multirow[t]{3}{*}{ Total Score (0-7) } & Acceptance & $4.9(1.4)$ & $4.2(1.8)$ \\
\hline & Pain control & $4.8(1.5)$ & $5.2(1.5)$ \\
\hline & No change & $4.0(1.3)$ & $3.9(1.2)$ \\
\hline \multicolumn{4}{|l|}{ Degrees of movement } \\
\hline \multirow[t]{3}{*}{ Flexion } & Acceptance & $61.2(31.9)$ & $61.3(36.2)$ \\
\hline & Pain control & $51.8(29.7)$ & $45.9(25.6)$ \\
\hline & No change & $65.9(36.2)$ & $70.5(40.6)$ \\
\hline \multirow[t]{3}{*}{ Extension } & Acceptance & $14.7(6.2)$ & $16.5(7.7)$ \\
\hline & Pain control & $15.3(6.2)$ & $13.7(6.2)$ \\
\hline & No change & $16.8(7.5)$ & $18.4(7.6)$ \\
\hline \multirow[t]{3}{*}{ Lateral Flexion } & Acceptance & $15.8(6.9)$ & $20.5(6.6)$ \\
\hline & Pain control & $15.9(6.5)$ & $18.0(6.8)$ \\
\hline & No change & $18.9(5.3)$ & $20.5(5.5)$ \\
\hline \multirow[t]{3}{*}{ Straight Leg Raise } & Acceptance & $39.3(18.6)$ & $38.7(20.4)$ \\
\hline & Pain control & $26.2(14.7)$ & $23.4(16.0)$ \\
\hline & No change & $41.4(17.8)$ & $43.3(20.9)$ \\
\hline \multicolumn{4}{|l|}{ Endurance time (sec) } \\
\hline \multirow[t]{3}{*}{ Active Straight Leg Raise } & Acceptance & $3.8(3.2)$ & $4.3(3.4)$ \\
\hline & Pain control & $4.0(4.2)$ & $4.8(4.3)$ \\
\hline & No change & $6.9(2.7)$ & $7.3(3.4)$ \\
\hline \multirow[t]{3}{*}{ Active Sit-up } & Acceptance & $5.9(3.9)$ & $5.7(3.7)$ \\
\hline & Pain control & $6.0(4.0)$ & $5.5(3.6)$ \\
\hline & No change & $8.4(3.1)$ & $7.8(3.1)$ \\
\hline
\end{tabular}

(table continues) 
Table 2 (con't)

\begin{tabular}{cccc}
\hline \% indicating positive finding & & & \\
\hline Spinal Tenderness & Acceptance & $96.2 \%$ & $88.5 \%$ \\
& Pain control & $82.6 \%$ & $82.6 \%$ \\
& No change & $92.0 \%$ & $92.0 \%$ \\
\hline
\end{tabular}

Note: $\mathrm{N}=74 ;$ Acceptance: $\mathrm{n}=26$; Pain control: $\mathrm{n}=23$; No change: $\mathrm{n}=25$. 
Table 3

Mean (Standard Deviation) Values for the Physical Impairment Index Pain Ratings

\begin{tabular}{|c|c|c|c|}
\hline & Group & Baseline & Post-Instructions \\
\hline \multirow[t]{3}{*}{ Average Pain } & Acceptance & $6.1(1.5)$ & $6.0(1.6)$ \\
\hline & Pain control & $5.9(1.2)$ & $6.0(1.4)$ \\
\hline & No change & $6.2(1.3)$ & $5.9(1.5)$ \\
\hline \multirow[t]{3}{*}{ Flexion } & Acceptance & $5.6(2.3)$ & $6.1(1.3)$ \\
\hline & Pain control & $6.2(1.3)$ & $6.3(1.4)$ \\
\hline & No change & $6.2(1.7)$ & $6.0(2.5)$ \\
\hline \multirow[t]{3}{*}{ Extension } & Acceptance & $6.0(1.4)$ & $5.9(1.7)$ \\
\hline & Pain control & $5.5(1.4)$ & $5.8(1.5)$ \\
\hline & No change & $6.0(1.6)$ & $5.8(1.6)$ \\
\hline \multirow[t]{3}{*}{ Lateral Flexion } & Acceptance & $5.8(2.0)$ & $5.8(1.8)$ \\
\hline & Pain control & $5.9(1.8)$ & $5.6(1.3)$ \\
\hline & No change & $5.9(1.5)$ & $5.8(1.7)$ \\
\hline \multirow[t]{3}{*}{ Spinal Tenderness } & Acceptance & $5.4(2.1)$ & $5.5(2.7)$ \\
\hline & Pain control & $4.9(2.4)$ & $5.0(2.5)$ \\
\hline & No change & $6.2(2.5)$ & $5.6(2.4)$ \\
\hline \multirow[t]{3}{*}{ Straight Leg Raise } & Acceptance & $7.4(1.7)$ & $6.4(1.9)$ \\
\hline & Pain control & $6.2(1.9)$ & $6.4(1.6)$ \\
\hline & No change & $6.3(2.3)$ & $5.9(1.7)$ \\
\hline \multirow[t]{3}{*}{ Active Straight Leg Raise } & Acceptance & $6.2(2.5)$ & $6.1(2.1)$ \\
\hline & Pain control & $6.2(1.6)$ & $6.9(1.6)$ \\
\hline & No change & $7.2(1.3)$ & $6.7(1.3)$ \\
\hline \multirow[t]{3}{*}{ Active Sit-up } & Acceptance & $6.2(1.9)$ & $6.2(1.6)$ \\
\hline & Pain control & $6.4(1.7)$ & $5.9(1.5)$ \\
\hline & No change & $5.8(1.6)$ & $5.4(2.2)$ \\
\hline
\end{tabular}

Note: $\mathrm{N}=74 ;$ Acceptance: $\mathrm{n}=26$; Pain control: $\mathrm{n}=23$; No change: $\mathrm{n}=25$. 
Table 4

Estimated Marginal Means (Standard Deviation) for Post-Instruction Physical Impairment Index values using baseline values as a covariate.

\begin{tabular}{|c|c|c|}
\hline & Group & Mean (SD) \\
\hline \multirow[t]{3}{*}{ Total Score (0-7) } & Acceptance & $3.8(0.2)$ \\
\hline & Pain control & $5.0(0.2)$ \\
\hline & No change & $4.4(0.2)$ \\
\hline \multicolumn{3}{|l|}{ Degrees of movement } \\
\hline \multirow[t]{3}{*}{ Flexion } & Acceptance & $60.1(3.1)$ \\
\hline & Pain control & $53.5(3.4)$ \\
\hline & No change & $64.7(3.2)$ \\
\hline \multirow[t]{3}{*}{ Extension } & Acceptance & $17.0(1.2)$ \\
\hline & Pain control & $13.8(1.3)$ \\
\hline & No change & $17.7(1.2)$ \\
\hline \multirow[t]{3}{*}{ Lateral Flexion } & Acceptance & $21.4(0.7)$ \\
\hline & Pain control & $18.8(0.8)$ \\
\hline & No change & $18.9(0.8)$ \\
\hline \multirow[t]{3}{*}{ Straight Leg Raise } & Acceptance & $35.2(1.5)$ \\
\hline & Pain control & $33.5(1.7)$ \\
\hline & No change & $37.6(1.6)$ \\
\hline \multicolumn{3}{|l|}{ Endurance time (sec) } \\
\hline \multirow[t]{3}{*}{ Active Straight Leg Raise } & Acceptance & $5.4(0.4)$ \\
\hline & Pain control & $5.6(0.5)$ \\
\hline & No change & $5.5(.05)$ \\
\hline \multirow[t]{3}{*}{ Active Sit-up } & Acceptance & $6.4(0.3)$ \\
\hline & Pain control & $6.1(0.4)$ \\
\hline & No change & $6.5(0.4)$ \\
\hline
\end{tabular}

Note: $\mathrm{N}=74 ;$ Acceptance: $\mathrm{N}=26$; Pain control: $\mathrm{N}=23$; No change: $\mathrm{N}=25$. 
Table 5

Average Raw Change (Standard Deviation) in Physical Impairment Index values

\begin{tabular}{|c|c|c|}
\hline & Group & Change \\
\hline \multirow[t]{3}{*}{ Total Score (0-7) } & Acceptance & $-0.8(0.9)$ \\
\hline & Pain control & $0.4(0.8)$ \\
\hline & No change & $0.1(0.7)$ \\
\hline \multicolumn{3}{|l|}{ Degrees of movement } \\
\hline \multirow[t]{3}{*}{ Flexion } & Acceptance & $0.2(13.2)$ \\
\hline & Pain control & $-5.9(17.1)$ \\
\hline & No change & $4.6(17.4)$ \\
\hline \multirow[t]{3}{*}{ Extension } & Acceptance & $1.8(5.5)$ \\
\hline & Pain control & $-1.7(9.4)$ \\
\hline & No change & $1.6(4.6)$ \\
\hline \multirow[t]{3}{*}{ Lateral Flexion } & Acceptance & $4.7(4.1)$ \\
\hline & Pain control & $2.1(4.8)$ \\
\hline & No change & $1.6(3.4)$ \\
\hline \multirow[t]{3}{*}{ Straight Leg Raise } & Acceptance & $-0.6(8.1)$ \\
\hline & Pain control & $-2.7(7.6)$ \\
\hline & No change & $1.8(7.2)$ \\
\hline \multicolumn{3}{|l|}{ Endurance time (sec) } \\
\hline \multirow[t]{3}{*}{ Active Straight Leg } & Acceptance & $0.5(1.5)$ \\
\hline & Pain control & $0.8(2.0)$ \\
\hline & No change & $0.4(2.7)$ \\
\hline \multirow[t]{3}{*}{ Active Sit-up } & Acceptance & $-0.2(1.6)$ \\
\hline & Pain control & $-0.5(2.5)$ \\
\hline & No change & $-0.6(1.3)$ \\
\hline
\end{tabular}

Note: $\mathrm{N}=74 ;$ Acceptance: $\mathrm{n}=26$; Pain control: $\mathrm{n}=23$; No change: $\mathrm{n}=25$. 
Table 6

Estimated Marginal Means (Standard Deviation) for Post-Instruction Physical Impairment Index Pain Ratings using baseline values as a covariate.

\begin{tabular}{|c|c|c|}
\hline & Group & Mean (SD) \\
\hline \multirow[t]{3}{*}{ Average Pain } & Acceptance & $5.99(.16)$ \\
\hline & Pain control & $6.18(.17)$ \\
\hline & No change & $5.75(.17)$ \\
\hline \multirow[t]{3}{*}{ Flexion } & Acceptance & $6.37(.28)$ \\
\hline & Pain control & $6.33(.30)$ \\
\hline & No change & $5.87(.29)$ \\
\hline \multirow[t]{3}{*}{ Extension } & Acceptance & $5.85(.21)$ \\
\hline & Pain control & $6.18(.23)$ \\
\hline & No change & $5.76(.22)$ \\
\hline \multirow[t]{3}{*}{ Lateral Flexion } & Acceptance & $5.84(.23)$ \\
\hline & Pain control & $5.80(.24)$ \\
\hline & No change & $5.79(.23)$ \\
\hline \multirow[t]{3}{*}{ Spinal Tenderness } & Acceptance & $5.75(.26)$ \\
\hline & Pain control & $5.71(.28)$ \\
\hline & No change & $5.05(.27)$ \\
\hline \multirow[t]{3}{*}{ Straight Leg Raise } & Acceptance & $6.03(.32)$ \\
\hline & Pain control & $6.81(.33)$ \\
\hline & No change & $6.10(.32)$ \\
\hline \multirow[t]{3}{*}{ Active Straight Leg Raise } & Acceptance & $6.36(.24)$ \\
\hline & Pain control & $7.12(.26)$ \\
\hline & No change & $6.29(.25)$ \\
\hline \multirow[t]{3}{*}{ Active Sit-up } & Acceptance & $6.16(.25)$ \\
\hline & Pain control & $5.65(.28)$ \\
\hline & No change & $5.68(.26)$ \\
\hline
\end{tabular}

Note: $\mathrm{N}=74 ;$ Acceptance: $\mathrm{n}=26$; Pain control: $\mathrm{n}=23$; No change: $\mathrm{n}=25$. 
Table 7

Average Raw Change (Standard Deviation) in Physical Impairment Index Pain Ratings

\begin{tabular}{|c|c|c|}
\hline & Group & Change \\
\hline \multirow[t]{3}{*}{ Average Pain } & Acceptance & $-.10(.93)$ \\
\hline & Pain control & $.07(.88)$ \\
\hline & No change & $-.13(.69)$ \\
\hline \multirow[t]{3}{*}{ Flexion } & Acceptance & $.46(2.12)$ \\
\hline & Pain control & $.10(1.22)$ \\
\hline & No change & $-.28(1.28)$ \\
\hline \multirow[t]{3}{*}{ Extension } & Acceptance & $-.11(1.28)$ \\
\hline & Pain control & $.29(.78)$ \\
\hline & No change & $-.20(1.19)$ \\
\hline \multirow[t]{3}{*}{ Lateral Flexion } & Acceptance & $-.04(1.40)$ \\
\hline & Pain control & $-.33(1.11)$ \\
\hline & No change & $-.12(1.17)$ \\
\hline \multirow[t]{3}{*}{ Spinal Tenderness } & Acceptance & $.11(1.40)$ \\
\hline & Pain control & $.10(1.58)$ \\
\hline & No change & $-.64(1.11)$ \\
\hline \multirow[t]{3}{*}{ Straight Leg Raise } & Acceptance & $-1.08(1.52)$ \\
\hline & Pain control & $.24(1.81)$ \\
\hline & No change & $-.36(2.36)$ \\
\hline \multirow[t]{3}{*}{ Active Straight Leg Raise } & Acceptance & $-.08(1.51)$ \\
\hline & Pain control & $.67(1.49)$ \\
\hline & No change & $-.48(.96)$ \\
\hline \multirow[t]{3}{*}{ Active Sit-up } & Acceptance & $.04(1.22)$ \\
\hline & Pain control & $-.52(1.36)$ \\
\hline & No change & $-.32(1.46)$ \\
\hline
\end{tabular}

Note: $\mathrm{N}=74 ;$ Acceptance: $\mathrm{n}=26$; Pain control: $\mathrm{n}=23$; No change: $\mathrm{n}=25$. 


\section{Table 8}

Descriptive Information for Follow-up Questionnaire

\begin{tabular}{lll}
\hline & \multicolumn{1}{c}{ Group } & Mean (SD) \\
\hline Change in Thinking & Acceptance & $5.7(1.8)$ \\
& Pain control & $5.1(2.9)$ \\
& No change & $4.8(2.3)$ \\
\hline Utility & Acceptance & $6.0(2.1)$ \\
& Pain control & $4.5(2.7)$ \\
& No change & $5.7(2.4)$ \\
\hline Effect on Performance & Acceptance & $5.0(2.3)$ \\
& Pain control & $4.9(2.8)$ \\
& No change & $5.2(2.8)$ \\
\hline
\end{tabular}

Note: $\mathrm{N}=74$; Acceptance: $\mathrm{n}=26$; Pain control: $\mathrm{n}=23$; No change: $\mathrm{n}=25$. 
Table 9

Correlations Among Physical Impairment Index Variables and Self-Report Measures

\begin{tabular}{lccccc}
\hline Measure & BDI-II & CPAQ & PASS-20 & MPQ-SF & FPQ-SF \\
\hline Total Score & .21 & -.05 & .19 & $.26^{*}$ & $.36^{* *}$ \\
Flexion & $-.23^{*}$ & .12 & -.07 & -.19 & $-.26^{*}$ \\
Extension & -.15 & -.06 & -.21 & -.11 & -.09 \\
Lateral Flexion & $-.38^{* *}$ & .06 & $-.45^{* * *}$ & $-.24^{*}$ & -.18 \\
Straight Leg Raise & $-.43^{* * *}$ & .14 & $-.26^{*}$ & $-.24^{*}$ & $-.41^{*}$ \\
Active Straight Leg Raise & -.20 & .13 & -.12 & -.12 & -.17 \\
Active Sit-up & -.12 & -.02 & -.13 & $-.27^{*}$ & $-.26^{*}$
\end{tabular}

Note. BDI-II: Beck Depression Inventory-II; CPAQ: Chronic Pain Acceptance Questionnaire; PASS-20:

Pain Anxiety Symptoms Scale-20; MPQ-SF: McGill Pain Questionnaire Short Form; FPQ-SF: Fear of

Pain Questionnaire-Short Form

${ }^{*} p \leq .05,{ }^{* *} p \leq .01,{ }^{* *} p \leq .001$ 
Table 10

Correlations Among Self-Report Measures

\begin{tabular}{lccccc}
\hline Measure & BDI-II & CPAQ & PASS-20 & MPQ-SF & FPQ-SF \\
\hline BDI-II & -- & $-.40^{* *}$ & $.67^{* *}$ & $.48^{* *}$ & .11 \\
CPAQ & & -- & $-.53^{* *}$ & $-.38^{* *}$ & -.09 \\
PASS-20 & & -- & $.48^{* *}$ & .15 \\
MPQ-SF & & & -- & $.33^{*}$ \\
FPQ-SF & & & & -- \\
\hline
\end{tabular}

Note. BDI-II: Beck Depression Inventory-II; CPAQ: Chronic Pain Acceptance Questionnaire; PASS-20:

Pain Anxiety Symptoms Scale-20; MPQ-SF: McGill Pain Questionnaire Short Form; FPQ-SF: Fear of Pain Questionnaire-Short Form.

${ }^{*} p \leq .005,{ }^{* *} p \leq .001$ 


\section{Figure Caption}

Figure 1. Physical Impairment Index total scores at baseline and post-instruction across groups. 


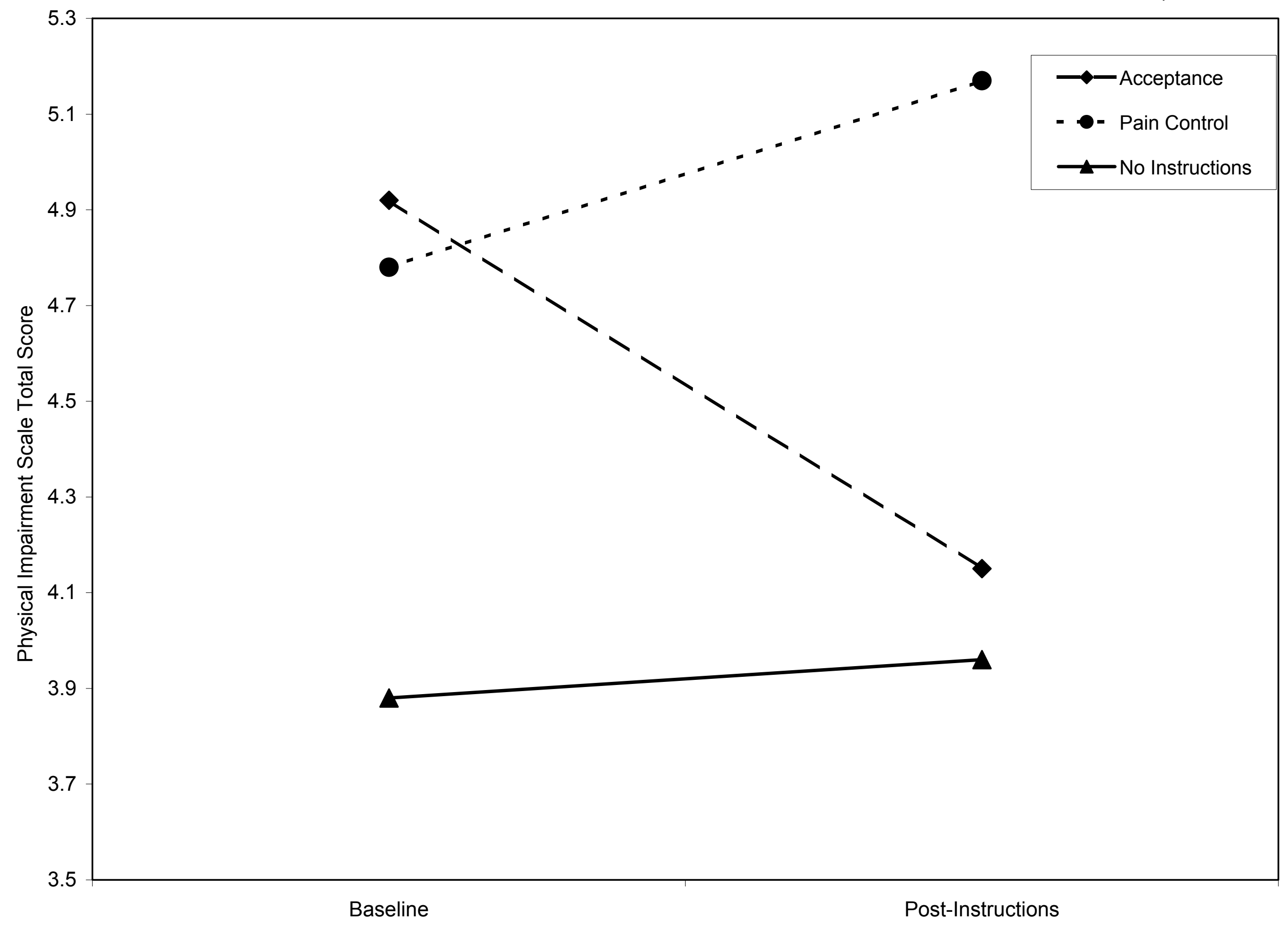

